Cíntia Beatriz de Souza Silva

\title{
Processamento de Sinais de Ressonância Magnética Nuclear Usando Classificador Neural para Reconhecimento de Carne Bovina
}

Dissertação apresentada à Escola de Engenharia de São Carlos da Universidade de São Paulo, sendo parte dos requisitos para obtenção do título de Mestre em Engenharia Elétrica.

Orientador: Prof. Dr. Ivan Nunes da Silva

São Carlos 

À minha mãe e ao meu irmão, pelo carinho e apoio incondicional durante a realização deste trabalho. 



\section{Agradecimentos}

Gostaria de agradecer a todos que me ajudaram na elaboração deste trabalho.

Ao professor Dr. Ivan Nunes da Silva pela orientação, incentivo e amizade.

Ao Dr. Luiz Alberto Colnago pela orientação na Embrapa, incentivo e amizade.

Ao Ricardo pelo apoio, carinho, companheirismo e compreensão.

A todos do grupo de ressonância, pela amizade e ajuda mútua.

Aos colegas do laboratório de automação inteligente de processos e sistemas, pelo apoio.

À Cátia por ceder os dados utilizados neste trabalho.

À Escola de Engenharia de São Carlos da USP pelo suporte acadêmico.

À Embrapa Instrumentação Agropecuária pela infra-estrutura.

Aos meus amigos e familiares. 



\section{Resumo}

SILVA, C. B. S. (2007). Processamento de Sinais de Ressonância Magnética Nuclear Usando Classificador Neural Para Reconhecimento de Carne Bovina. Dissertação (Mestrado) - Escola de Engenharia de São Carlos, Universidade de São Paulo, 2007.

Garantir a qualidade da carne bovina produzida no Brasil tem sido uma preocupação dos produtores, pois contribui para aumentar a exportação e o consumo interno do produto. Por isso, tem-se pesquisado novos métodos que analisam e garantam a qualidade da carne, de forma rápida, eficiente e não destrutiva. A Ressonância Magnética Nuclear (RMN) tem se destacado como uma das técnicas de controle de qualidade de carne. Neste trabalho as redes neurais artificiais estão sendo utilizadas para o reconhecimento de padrões dos dados de ressonância magnética nuclear oriundos de carne bovina. Mais especificamente, os respectivos dados têm sido utilizados por uma rede perceptron multicamadas para a extração de características da carne bovina, possibilitando a classificação do grupo genético e do sexo dos animais a partir de uma amostra da referida carne. Os resultados dos experimentos são também apresentados para ilustrar o desempenho da abordagem proposta.

Palavras chave: Redes neurais artificiais, ressonância magnética nuclear, classificação de padrões. 



\begin{abstract}
SILVA, C. B. S. (2007). Signal Processing of Nuclear Magnetic Resonance Using Neural Classification for Bovine Meat Recognition. Dissertation (Master's Degree) - Escola de Engenharia de São Carlos, Universidade de São Paulo, 2007.

Guaranteeing the quality of the bovine meat produced in Brazil has been a concern of the producers because it contributes to increase the export and the domestic consumption of the product. Therefore, new methods have been researched that analyze and guarantee the quality of the meat in a fast, efficient and non destructive way. Nuclear Magnetic Resonance (NMR) has been highlighted as one of the techniques of meat quality control. In this work study artificial neural networks are being used for pattern recognition from data obtained by the resonance equipment, originating from bovine meat. More specifically, the respective data have been used by a multilayer perceptron network for extraction of bovine meat characteristics, making possible the classification of both genetic group and animal sex starting from a single meat sample. Several results of experimental tests are also presented to illustrate the performance of the proposed approach.
\end{abstract}

Keywords: Artificial neural network, nuclear magnetic resonance, pattern classification. 



\section{Lista de Siglas e Abreviaturas}

$\begin{array}{ll}\text { AX } & \text { Animais cruzados filhos de touros da raça Angus } \\ \text { BX } & \text { Animais cruzados filhos de touros da raça Bosmara } \\ \text { CLA } & \text { Capacidade de Ligação da Água } \\ \text { CPMG } & \text { Carr-Purcell-Meiboom-Gill } \\ \text { CRA } & \text { Capacidade de Retenção de Água } \\ \text { CWFP } & \text { Continuous-Wave-Free-Precession } \\ \text { CX } & \text { Animais cruzados filhos de touros da raça Canchim } \\ \text { FID } & \text { Free Induction Decay } \\ \text { MLP } & \text { Multilayer Perceptron } \\ \text { RF } & \text { Rádio Freqüência } \\ \text { RMN } & \text { Ressonância Magnética Nuclear } \\ \text { RNA } & \text { Redes Neurais Artificiais } \\ \text { SSFP } & \text { Steady-State Free Precession } \\ \text { TA } & \text { Animais filhos de vacas cruzadas Angus x Nelore } \\ \text { TS } & \text { Animais filhos de vacas cruzadas Simental x Nelore }\end{array}$





\section{Lista de Símbolos}

$\begin{array}{ll}\mathrm{B}_{0} & \text { Campo magnético externo } \\ \mathrm{B}_{1} & \text { Campo magnético oscilante } \\ \mathrm{J} & \text { Momento angular intrínseco } \\ \mathrm{T}_{0} & \text { Magnetização resultante } \\ \mathrm{T}_{1} & \text { Constante de tempo de relaxação longitudinal } \\ \mathrm{T}_{2} & \text { Constante de tempo de relaxação transversal } \\ \mathrm{T}_{2}{ }^{*} & \text { Constante de tempo de relaxação sob efeito da não homogeneidade } \\ \Delta \mathrm{B}_{0} & \text { Não homogeneidade do campo } \\ \alpha & \text { Nível de menor energia } \\ \beta & \text { Nível de maior energia } \\ \mu & \text { Momento magnético nuclear } \\ \tau & \text { Duração do pulso (pw) }\end{array}$





\section{Lista de Figuras}

FIGURA 1.1 - Subdivisão da meia carcaça indicando traseiro, dianteiro e ponta de agulha, bem como a sexta e a décima segunda costelas do contrafilé. 3

FIGURA 2.1 - Diagrama do estado degenerado e após a aplicação do campo $B_{0}$...9

FIGURA 2.2 - Movimento de rotação do spin. 10

FIGURA 2.3 - Centro de carga para uma condição de carga pesada. 10

FIGURA 2.4 - (a) Magnetização resultante. (b) Comportamento da magnetização durante o pulso.

FIGURA 2.5 - Esquema vetorial do fenômeno da relaxação longitudinal 12

FIGURA 2.6 - Relaxação transversal. 13

FIGURA 2.7 - Seqüência de pulsos do método de CPMG. 15

FIGURA 2.8 - Sinais de RMN de uma amostra de 2,2 mg de óleo vegetal obtidos com a técnica de análise do FID (a) e CWFP (b) em 1,38s.

FIGURA 2.9 - Representação do sinal do CWFP para amostra de ácido fosfórico

( $\left.{ }^{1} H\right)$ com $T_{1}=190$ ms e $T_{2}=140$ ms. (a) Regime de alternância de intensidade, (b) Estado quase-estacionário e (c) Estado verdadeiramente-estacionário. 18

FIGURA 2.10 - Representação da estrutura muscular macroscópica.......................19

FIGURA 3.1 - Representação de um neurônio biológico.........................................28

FIGURA 3.2 - Representação de um neurônio artificial.........................................29

FIGURA 3.3 - Funções de ativação e suas equações............................................30

FIGURA 3.4 - Comparação entre o neurônio biológico e o artificial. ..........................31

FIGURA 3.5 - Rede feedforward ou acíclica de única camada. ................................32 
FIGURA 3.6 - Rede feedforward ou acíclica com uma camada intermediária e uma

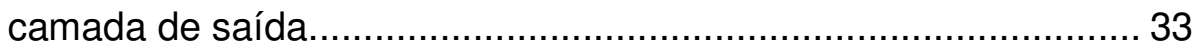

FIGURA 3.7 - Rede recorrente com realimentação. ............................................ 34

FIGURA 3.8 - Fluxo do processamento do algoritmo back-propagation.................. 39

FIGURA 4.1 - Grupo genético dos pais e das mães dos animais analisados.......... 46

FIGURA 4.2 - Janela de preparação dos dados para a classificação por redes

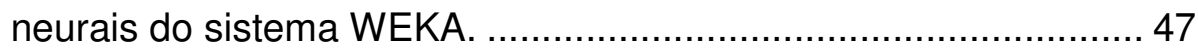

FIGURA 4.3 - Equipamento de ressonância magnética nuclear............................ 48

FIGURA 4.4 - Parte eletrônica ligada ao equipamento de RMN.............................. 48

FIGURA 4.5 - Diagrama em blocos de um espectrômetro de RMN......................... 49

FIGURA 4.6 - Foto de um bife de contra-filé utilizado nas análises.........................50

FIGURA 4.7 - Curva de decaimento de CWFP das amostras de carnes bovinas relacionadas ao sexo dos animais.

FIGURA 4.8 - Curva de decaimento de CPMG das amostras de carnes bovinas relacionadas ao grupo genético. .................................................. 51

FIGURA A.1 - Dados armazenados em formato de planilha...................................... 83

FIGURA A.2 - Dados armazenados em formato de texto. ..................................... 83

FIGURA A.3 - Dados armazenados em formato ARFF...................................... 84

FIGURA A.4 - Ilustração de tarefas de pré-processamento disponibilizadas pelo

WEKA. 85

FIGURA A.5 - Ilustração de tarefas de classificação disponibilizadas pelo WEKA.. 86

FIGURA A.6 - Ilustração da janela de seleção de atributos do WEKA. ……........... 88 


\section{Lista de Tabelas}

TABELA 4.1 - Parâmetros de treinamento da MLP (CPMG) - Classificação do grupo genético (TA) com dados não igualmente espaçados.

.53

TABELA 4.2 - Parâmetros de treinamento da MLP (CPMG) - Classificação do grupo genético (TS) com dados não igualmente espaçados......................54

TABELA 4.3 - Parâmetros de treinamento da MLP (CPMG) - Classificação do grupo genético $(\mathrm{AX})$ com dados não igualmente espaçados.

TABELA 4.4 - Parâmetros de treinamento da MLP (CPMG) - Classificação do grupo genético (BX) com dados não igualmente espaçados. .55

TABELA 4.5 - Parâmetros de treinamento da MLP (CPMG) - Classificação do grupo genético $(C X)$ com dados não igualmente espaçados. .56

TABELA 4.6 - Parâmetros de treinamento da MLP (CWFP) - Classificação do grupo genético (TA) com dados igualmente espaçado.

TABELA 4.7 - Parâmetros de treinamento da MLP (CWFP) - Classificação do grupo genético (TS) com os dados igualmente espaçados. .57

TABELA 4.8 - Parâmetros de treinamento da MLP (CWFP) - Classificação do grupo genético $(\mathrm{AX})$ com dados não igualmente espaçados. .58

TABELA 4.9 - Parâmetros de treinamento da MLP (CWFP) - Classificação do grupo genético (BX) com dados não igualmente espaçados.

TABELA 4.10 - Parâmetros de treinamento da MLP (CWFP) - Classificação do grupo genético (CX) com dados não igualmente espaçado. 59

TABELA 4.11 - Parâmetros de treinamento da MLP (CPMG) - Classificação do sexo. 
TABELA 4.12 - Parâmetros de treinamento da MLP (CWFP) - Classificação do sexo.

TABELA 4.13 - Acurácia da MLP (CPMG) para estimativa do grupo genético dos animais $(\mathrm{TA})$.

TABELA 4.14 - Acurácia da MLP (CPMG) para estimativa do grupo genético dos animais (TS).

TABELA 4.15 - Acurácia da MLP (CPMG) para estimativa do grupo genético dos animais (AX).

TABELA 4.16 - Acurácia da MLP (CPMG) para estimativa do grupo genético dos animais (BX).

TABELA 4.17 - Acurácia da MLP (CPMG) para estimativa do grupo genético dos animais (CX).

TABELA 4.18 - Acurácia da MLP (CWFP) para estimativa do grupo genético dos animais $(\mathrm{TA})$.

TABELA 4.19 - Acurácia da MLP (CWFP) para estimativa do grupo genético dos animais (TS). 66

TABELA 4.20 - Acurácia da MLP (CWFP) para estimativa do grupo genético dos animais $(A X)$.

TABELA 4.21 - Acurácia da MLP (CWFP) para estimativa do grupo genético dos animais (BX).

TABELA 4.22 - Acurácia da MLP (CWFP) para estimativa do grupo genético dos animais CX).

TABELA 4.23 - Acurácia da MLP (CPMG) para estimativa do sexo dos animais... 67 TABELA 4.24 - Acurácia da MLP (CWFP) para estimativa do sexo dos animais. .. 68 


\section{SUMÁRIO}

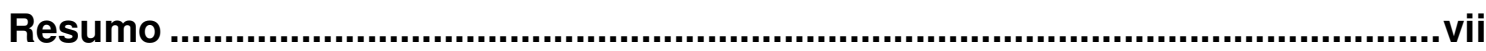

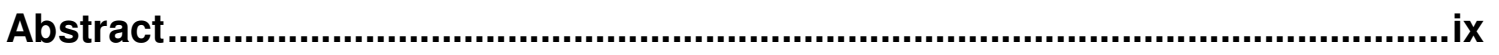

Lista de Siglas e Abreviaturas .........................................................................

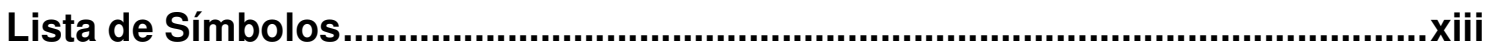

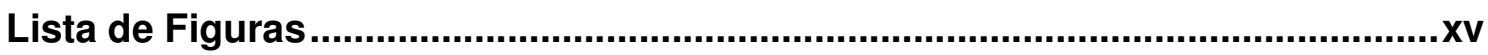

Lista de Tabelas ................................................................................................

1 Introdução

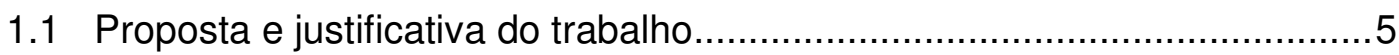

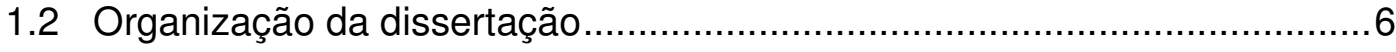

2 Aspectos do Processo de Ressonância Magnética Nuclear ..........................7

2.1 Princípios de ressonância magnética nuclear ........................................

2.1.1 Relaxação longitudinal ...................................................... 12

2.1.2 Relaxação transversal ....................................................... 13

2.1.3 Seqüência de pulsos de CPMG (Carr-Purcell-Meiboom-Gil).......... 14

2.1.4 Seqüência de pulsos de CWFP (Continuous Wave Free

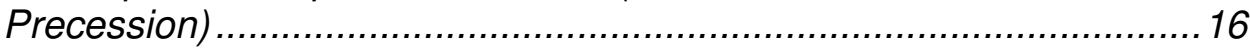

2.2 Transformação do músculo em carne ................................................. 18

2.3 Aplicações de ressonância magnética no controle de qualidade de

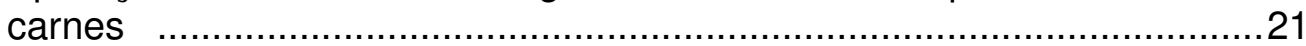

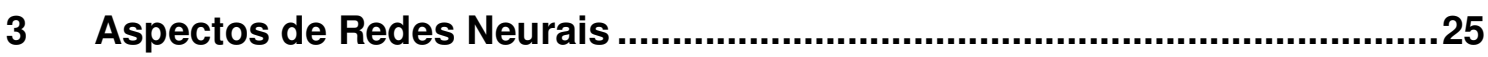

3.1 Modelo de Neurônio biológico e modelo de neurônio artificial .................27

3.2 Arquitetura de redes neurais artificiais ...................................................

3.2.1 Feedforward de única camada ...............................................32

3.2.2 Feedforward de múltiplas camadas .............................................33

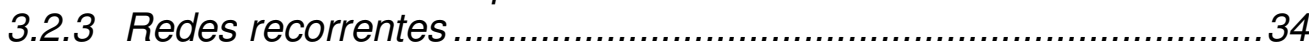

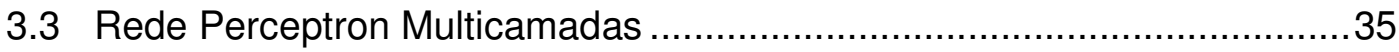

3.4 Treinamento de redes Perceptron Multicamadas ....................................38

3.5 Aplicações de redes neurais artificiais no controle de qualidade de alimentos

4 Processamento de Sinais de Ressonância Magnética Nuclear para Classificação de Carne Bovina Usando Redes Neurais Artificiais ..............45

4.1 Obtenção dos sinais de ressonância magnética nuclear .........................4 47

4.2 Arquitetura neural para classificação de carne bovina referente ao grupo genético 
4.3 Arquitetura neural para a classificação de carne bovina referente ao sexo do animal.....

4.4 Resultados das aplicações das arquiteturas neurais desenvolvidas ........ 63

4.5 Considerações sobre os resultados obtidos ......................................... 68

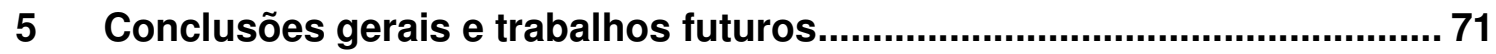

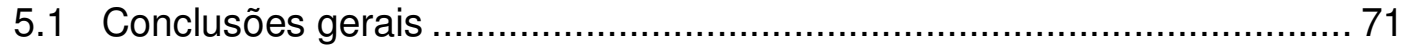

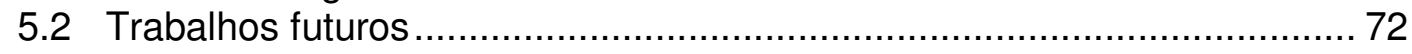

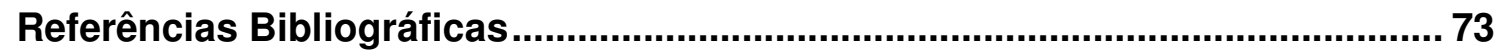

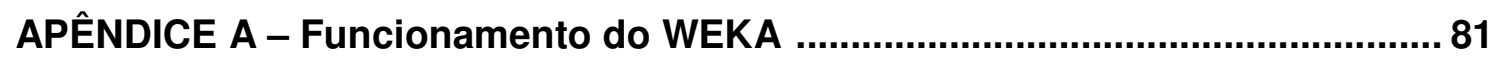




\section{Introdução}

O Brasil vem aumentando a cada ano a sua produção e exportação de carne bovina. Ao mesmo tempo, os consumidores vêm cada vez mais exigindo produtos de qualidade nutricional, sanitária e que possuam rastreamento, assegurando a qualidade e procedência do produto. As características desejadas e observadas pelos consumidores, no momento da compra, são as seguintes: a cor, a maciez, o sabor e a suculência. A suculência depende da sensação de umidade nos primeiros movimentos mastigatórios, ou seja, da liberação de líquidos pela carne [12].

De modo geral, pode-se dizer que a qualidade da carne depende da interação de fatores intrínsecos e extrínsecos. Os fatores intrínsecos mais importantes são a genética, o manejo alimentar, a idade e o sexo do animal. Dentre os fatores extrínsecos, os mais importantes são as condições de abate (desde a saída dos animais da propriedade até a entrada das carcaças nas câmaras frias), o tipo de cozimento e os métodos de conservação [1].

Além disso, a cor da carne, a gordura, odor e sabor, firmeza e textura, maciez e suculência estão relacionadas com a qualidade da carne bovina. É desejável que o animal possua uma musculatura rígida permitindo que o corte apresente textura fina e homogênea e músculos de coloração vermelha brilhante e a gordura clara [17]. 
A carne dos bovinos criados no pasto geralmente é mais dura e possui uma maior concentração de mioglobina, isso acontece porque eles se exercitam e são abatidos mais velhos. A mioglobina é o principal pigmento da carne.

A habilidade da carne em reter água durante a aplicação de forças externas é conhecida como capacidade de retenção de água (CRA) e é um dos fatores que influencia a firmeza da carne. A CRA é um parâmetro qualitativo de primeira importância na indústria da carne, uma vez que características sensoriais de tal produto, bem como a adequação a estoque e processamento, são influenciados pela CRA.

A perda de água pode ser descrita em três passos: (i) perda de água de dentro das miofibrilas devido ao encurtamento pós-morte; (ii) relocalização da água nos compartimentos intra para extracelular e (iii) fluxo subseqüente desse líquido para a superfície [30].

Atualmente, o método internacionalmente conhecido e utilizado para análise da qualidade de carne é o método desenvolvido nos Estados Unidos, que utiliza o contra-filé na região da décima segunda costela. Por essa região ser exatamente no meio da peça os frigoríficos brasileiros têm se recusado a adotar tal método. Por tal razão, tem-se buscado a sua substituição. Uma alternativa foi utilizar a região da sexta costela do contra-filé; assim, não seria mais necessário dividir a peça para fazer análises de qualidade. A Figura 1.1 ilustra a região da sexta e da décima segunda costela na peça de contra-filé. 


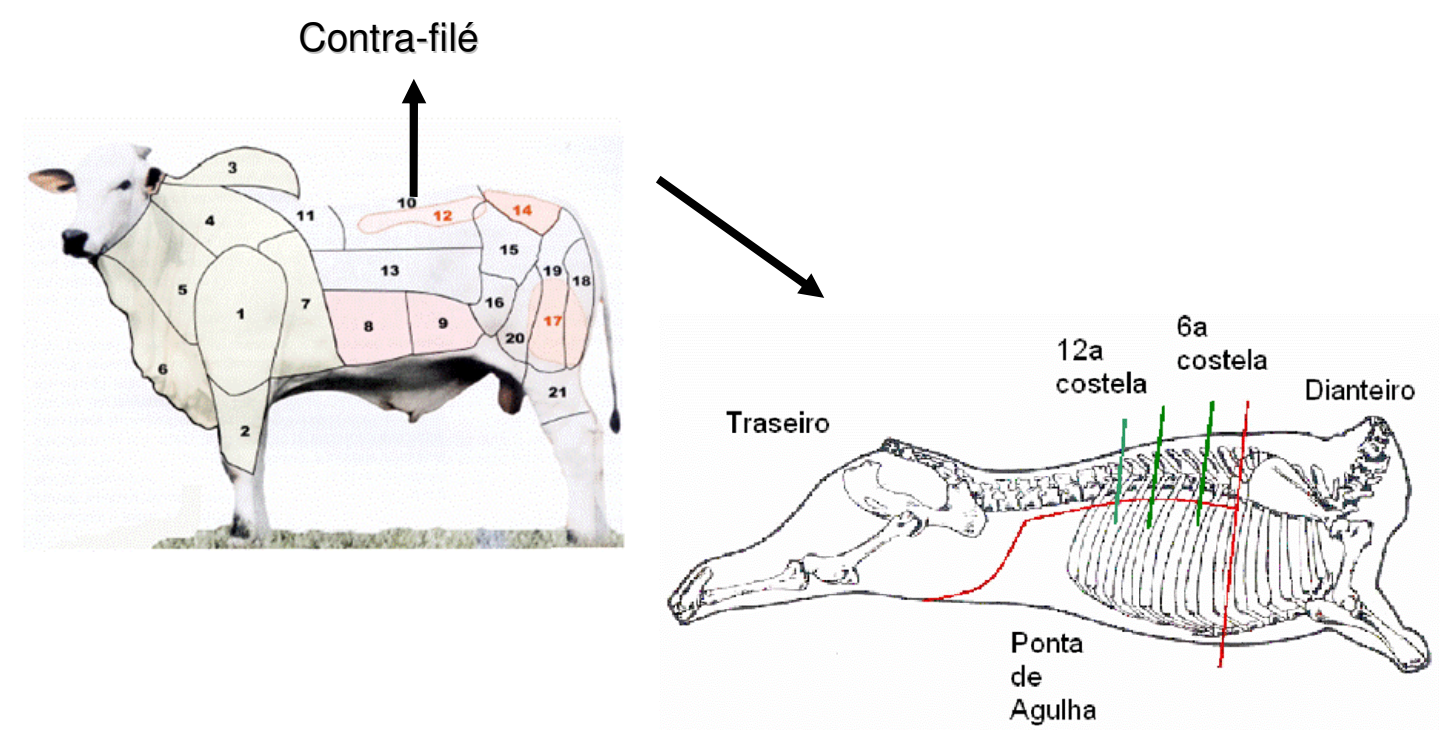

FIGURA 1.1 - Subdivisão da meia carcaça indicando traseiro, dianteiro e ponta de agulha, bem como a sexta e a décima segunda costelas do contra-filé.

Para prever a qualidade da carne, novos métodos físicos de análise estão sendo desenvolvidos, permitindo fazer análises rápidas, não invasivas e também não destrutivas da qualidade da carne. Dentre essas técnicas, a Ressonância Magnética Nuclear (RMN) já vem sendo avaliada principalmente para a carne suína.

Neste caso, a RMN tem sido usada para avaliação do pH, Capacidade de Retenção de Água (CRA), Capacidade de Ligação da Água (CLA), teor e distribuição de gordura, dentre outros parâmetros físico-químicos que estão diretamente relacionados com a qualidade nutricional e sensorial da carne [2,3]. Essas análises vêm sendo feitas com métodos de regressão linear simples, transformada inversa de Laplace e métodos de análise multivariadas, tais como análise de componentes principais, análise de clusters e mínimos quadrados parciais.

Ultimamente, métodos mais rápidos e eficientes de se analisar os dados gerados por essas novas técnicas têm sido pesquisados, e redes neurais artificiais têm apresentado resultados promissores, obtendo um melhor desempenho em 
relação aos métodos tradicionais. Isso acontece devido à sua capacidade de se adaptar em relação aos dados apresentados, extraindo o conhecimento necessário que permite classificar diversos atributos relacionados à qualidade da carne.

Para o desenvolvimento deste trabalho, utilizaram-se como amostras animais machos e fêmeas com a mesma idade, abatidos em cinco dias diferentes, onde no primeiro e no terceiro dia foram abatidos apenas fêmeas e no segundo, quarto e quinto dia apenas machos. Esses animais foram criados em confinamento, sendo abatidos precocemente com a idade de 1 ano. As características da carne desses bovinos são muito parecidas e comparadas à carne de bovinos criados no pasto sua carne é muito mole.

As amostras de carne frescas, provenientes de tais animais, foram fornecidas pela EMBRAPA Pecuária Sudeste e enviadas para a EMBRAPA Instrumentação Agropecuária, onde tais amostras foram analisadas no equipamento de RMN.

São observados alguns fenômenos que ocorrem na carne após o abate e o rigor mortis é um dos fenômenos mais importantes, por estar ligado ao processo de conversão do músculo em carne. Esse processo é caracterizado pela rigidez do músculo após a morte do animal. Durante o abate o animal fica mais agitado, com isso o nível de pH aumenta, conseqüentemente, o músculo fica mais rígido. Devese esperar um tempo após a morte do animal para que esse nível de pH diminua, conservando-o em uma temperatura baixa, em torno de zero grau, para que não haja proliferação de bactérias [16].

Esses processos físico-químicos que antecedem a transformação do músculo em carne estão diretamente relacionados com a maciez da carne. 


\subsection{Proposta e justificativa do trabalho}

O objetivo desse trabalho é desenvolver uma abordagem neural para processamento de sinais de ressonância magnética nuclear para a classificação de carnes bovinas.

Para aumentar o consumo e a exportação é necessário assegurar a qualidade da carne. Isso faz com que o Brasil necessite de leis específicas que garantam que produtores e frigoríficos façam testes nutricionais e sensoriais na carne para garantir a sua qualidade.

Novas técnicas vêm sendo desenvolvidas para que essas análises sejam feitas de forma rápida e não destrutiva. Isso tem contribuído no aumento das pesquisas utilizando RMN e a busca de métodos que possam analisar tais dados também de forma rápida. Uma alternativa é a utilização de redes neurais do tipo perceptron multicamadas, utilizando-as como classificadora de padrões.

Trabalhos que utilizam RMN em parceria com redes neurais podem ser encontrados na literatura, mas em análise das características da carne bovina ainda inexistem. Desta forma, esse trabalho foi elaborado utilizando os dados advindos de ressonância magnética nuclear como atributos de entradas para a rede perceptron multicamadas, visando a construção de um classificador do sexo e do grupo genético dos animais. 


\subsection{Organização da dissertação}

Nesta seção será apresentada uma breve introdução sobre o conteúdo abordado em cada capítulo.

No Capítulo 2 serão apresentados os conceitos básicos para o entendimento da ressonância magnética nuclear, a definição dos aspectos da ressonância magnética nuclear de baixo campo, os conceitos de transformação do músculo em

carne e a apresentação de algumas aplicações de ressonância magnética nuclear no controle de qualidade de alimentos.

No Capítulo 3 serão descritos alguns fundamentos teóricos da rede neural artificial, as principais características da rede perceptron multicamandas e algumas aplicações de redes neurais artificiais no controle de qualidade de alimentos.

No Capítulo 4 se encontra a descrição do funcionamento de um equipamento de RMN, os tipos de amostras usadas para a extração dos sinais, os parâmetros utilizados pela rede perceptron multicamadas na classificação do grupo genético e do sexo dos bovinos e seus resultados obtidos.

No Capítulo 5 serão feitas as considerações finais a respeito deste trabalho, denotando o desempenho apresentado pela classificação da rede e a descrição de propostas futuras, utilizando as amostras deste estudo. 


\section{Aspectos do Processo de Ressonância}

\section{Magnética Nuclear}

A espectroscopia de Ressonância Magnética Nuclear (RMN) é uma das mais importantes técnicas de química analítica, tendo aplicações em medicina, agricultura, alimentos, petroquímica, dentre outras. Esta técnica se divide em alta e baixa resolução. A espectroscopia de alta resolução em alto campo emprega ímãs de alto campo e boa homogeneidade, sendo possível realizar estudos muito mais refinados, baseados na estrutura química e mediados por deslocamento químico. Nesses equipamentos os sinais de RMN são adquiridos no domínio do tempo e processados com a transformada de Fourier para gerar os espectros no domínio da freqüência [24].

Nos espectrômetros de baixa resolução o sinal de RMN no domínio do tempo é usado diretamente na análise quantitativa ou qualitativa e se caracteriza por um decaimento exponencial que é relativo aos tempos de relaxação do sistema e a baixa homogeneidade do campo magnético.

As principais vantagens da $\mathrm{RMN}$ sobre os métodos convencionais de análise química são as seguintes: rapidez da análise, não-destruição da amostra e possibilidade de realizar análises em tecidos vegetais "in vivo". Outra vantagem da 
RMN é que o sistema pode ser automatizado, podendo então analisar em alguns casos até 20 mil amostras por hora.

\subsection{Princípios de ressonância magnética nuclear}

O fenômeno de RMN é observado em todos os isótopos que contenham spin nuclear total diferente de zero. Dentre esses isótopos, destaca-se o hidrogênio $\left({ }^{1} \mathrm{H}\right)$ que está presente na natureza em alta quantidade, como na água, que compõe a maior parte dos seres vivos. Assim, as análises por RMN de hidrogênio são as mais usadas como, por exemplo, no diagnóstico médico por imagens.

Os spins são núcleos magnéticos que na ausência de campo magnético se encontram no estado degenerado, ou seja, sem separação dos níveis de energia. Na presença de um campo magnético $B_{0}$, essa degenerescência é quebrada e os spins se alinham de acordo com a direção do campo, resultando na separação dos níveis de Zeeman [3] em dois níveis de energia, $\alpha$ e $\beta$, onde $\alpha$ representa o nível de menor energia por estar a favor do campo e $\beta$ o nível de maior energia por estar contra o campo magnético.

Esse alinhamento é conhecido como magnetização, sendo que o resultado não é instantâneo e leva cerca de 5 vezes o tempo de relaxação longitudinal ou spin-rede, caracterizado por uma constante de tempo $T_{1}$.

A Figura 2.1 mostra um diagrama com os spins degenerados (Figura 2.1(a)) e na presença de um campo magnético (Figura 2.1(b)). Neste último caso, pode-se observar a separação dos níveis de Zeeman $(\alpha$ e $\beta)$. 

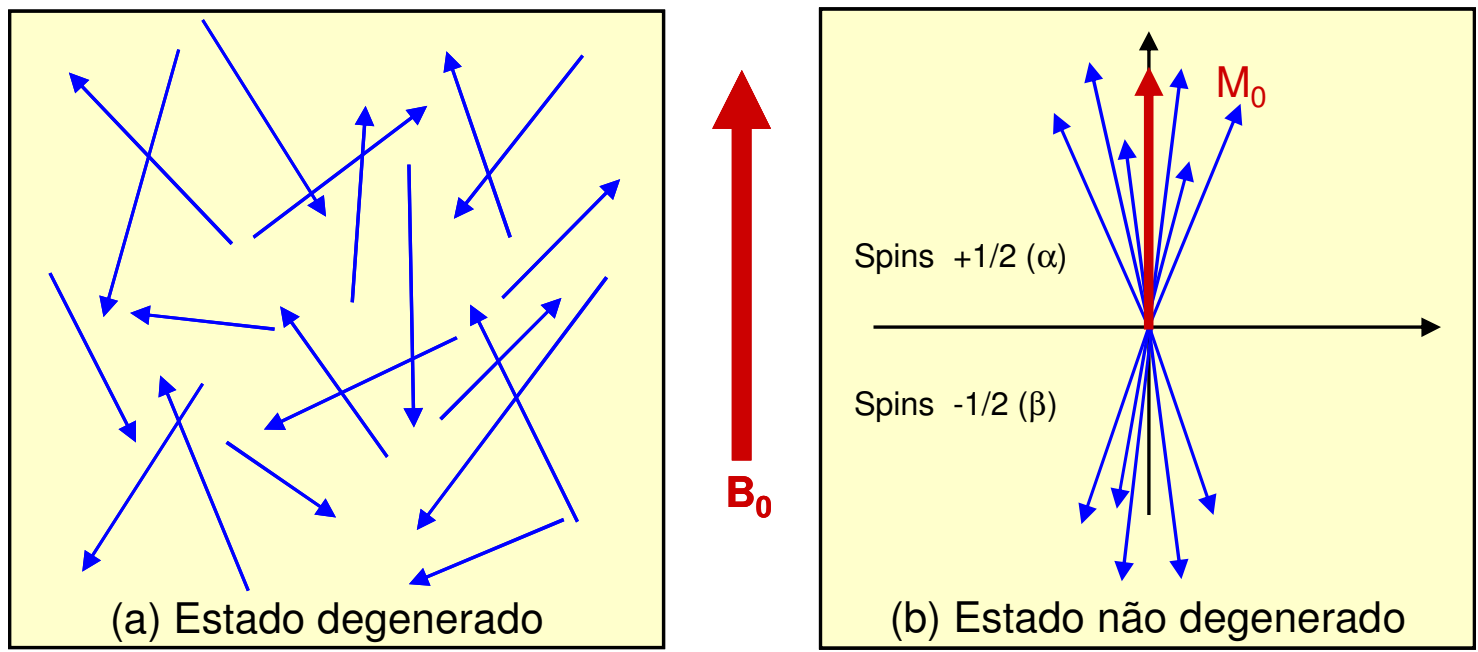

FIGURA 2.1 - Diagrama do estado degenerado e após a aplicação do campo $B_{0}$.

Alguns núcleos atômicos possuem a propriedade de se comportarem como pequenos dipolos magnéticos, ou seja, pequenos ímãs. Por esse ímã ser muito pequeno, o magnetismo do núcleo não contribui de forma mensurável para as propriedades magnéticas dos sólidos; porém, sem essa propriedade não se observa o fenômeno RMN [17].

O movimento de rotação de núcleos carregados em torno de um de seus eixos dá origem ao ímã. Esse movimento é conhecido como spin nuclear e expresso em termos de um número quântico chamado de número quântico de spin. Tal valor quantizado assume valores inteiros ou semi-inteiros $(1 / 2,1,3 / 2, \ldots)$ [22]. $\mathrm{O}$ momento angular de spin (J) é uma grandeza vetorial quantizada. Isto quer dizer que o vetor momento não pode assumir qualquer módulo, direção e sentido. O ímã que surge devido ao movimento de spin nuclear é denominado momento magnético nuclear $(\mu)$.

A Figura 2.2 apresenta o movimento giratório realizado pelo spin em torno do seu próprio eixo [13]. 


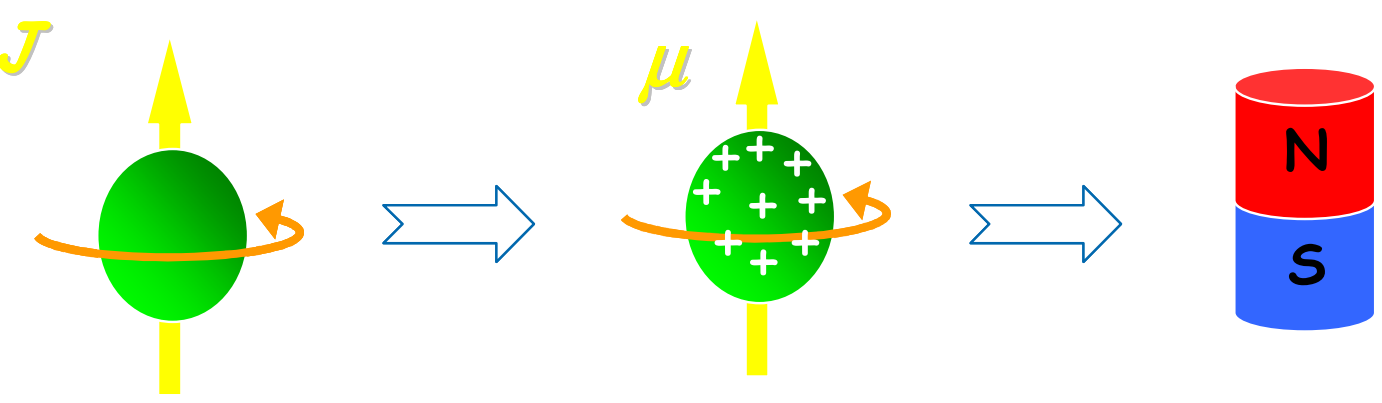

FIGURA 2.2 - Movimento de rotação do spin.

Ao se colocar uma amostra em um campo magnético estático o momento magnético nuclear adquire um movimento de precessão em torno de $\mathrm{B}_{0}$ e esse movimento é análogo ao movimento de um pião ao redor do campo gravitacional da terra, conforme ilustra a Figura 2.3 [13].
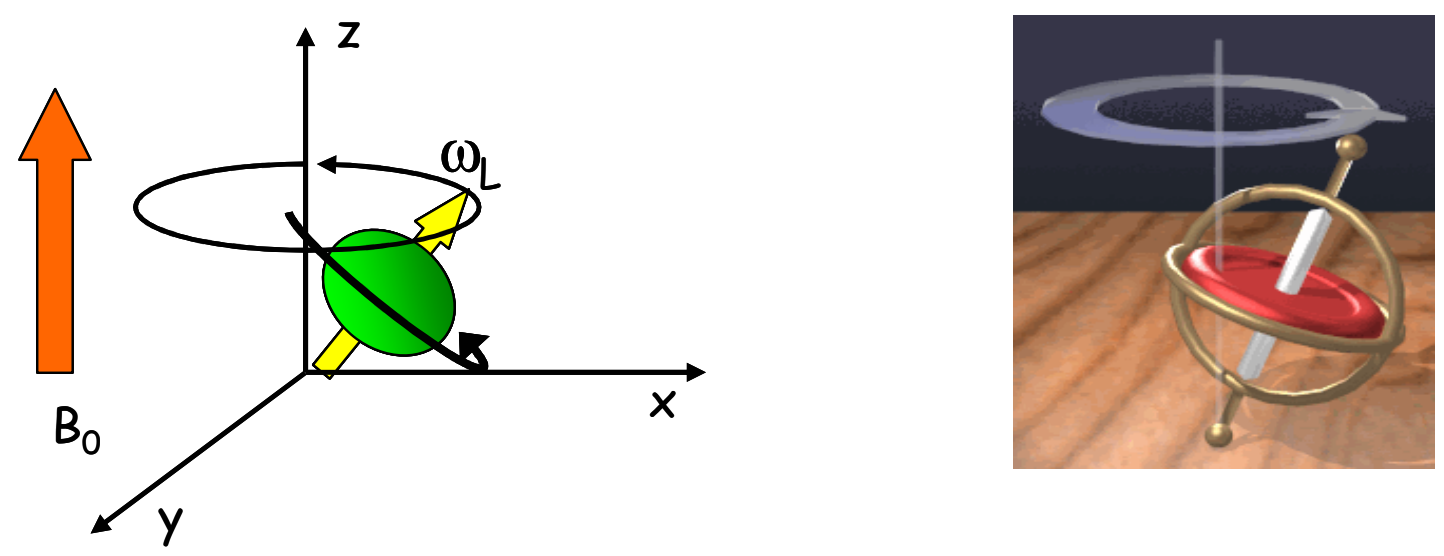

FIGURA 2.3 - Centro de carga para uma condição de carga pesada.

O fenômeno de RMN ocorre quando incide sobre a amostra um campo oscilante $B_{1}$, com freqüência igual à freqüência de precessão, também conhecida como freqüência de Larmor [3]. Com isso, os spins adquirem energia e mudam de estado. 
A Figura 2.4 mostra o efeito da aplicação de campo magnético oscilante $\left(B_{1}\right)$, aplicado perpendicularmente ao campo $B_{0}$. O pulso de radiofreqüência $(R F)$ exerce um torque sobre $\mathrm{M}$, deslocando seu eixo de rotação na direção do plano xy.

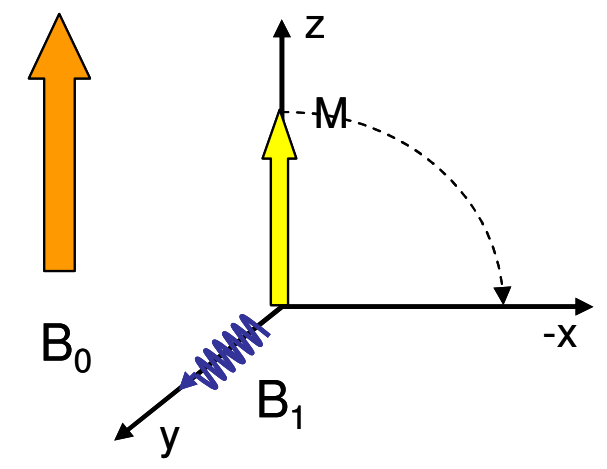

(a)

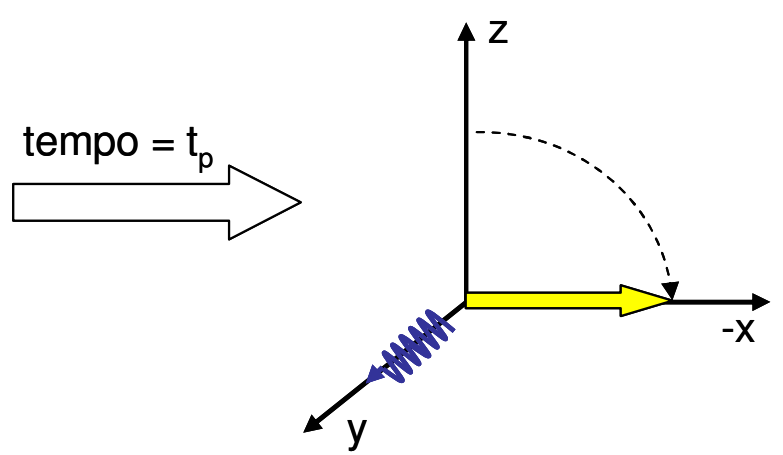

(b)

FIGURA 2.4 - (a) Magnetização resultante. (b) Comportamento da magnetização durante o pulso.

Após o pulso, a magnetização nuclear tende a girar em torno da direção do campo com uma freqüência igual à freqüência de Larmor, induzindo em uma bobina o sinal de RMN.

Com o término da aplicação do campo magnético $B_{1}$, a magnetização resultante $\mathrm{M}$ que foi alterada em módulo e orientação tende a voltar para o seu estado inicial de equilíbrio, passando a atuar no sistema o fenômeno da relaxação. Dois mecanismos distintos são envolvidos no processo de relaxação: relaxação transversal e relaxação longitudinal. 


\subsubsection{Relaxação longitudinal}

O processo de relaxação longitudinal, também chamado de relaxação spinrede, consiste no restabelecimento da distribuição das populações dos níveis de energia Zeeman. O excesso de energia potencial magnética é transferido do estado excitado para a vizinhança ou para a rede, na forma de energia cinética molecular.

Este fenômeno de emissão não é espontâneo, mas sim o resultado da interação dos momentos magnéticos nucleares com os campos magnéticos dos núcleos que compõem a rede e que oscilam em torno da freqüência de Larmor, sendo capaz de absorver esta energia.

O tempo de relaxação longitudinal é caracterizado pela constante $T_{1}$. Para evitar a saturação do sinal e garantir um retorno de aproximadamente $99 \%$ da magnetização ao estado de equilíbrio térmico, cada seqüência de pulso deverá ser precedida por um intervalo de $5 \mathrm{~T}_{1}$ para que esse retorno aconteça.

A Figura 2.5 descreve o retorno da componente longitudinal ao valor de equilíbrio.
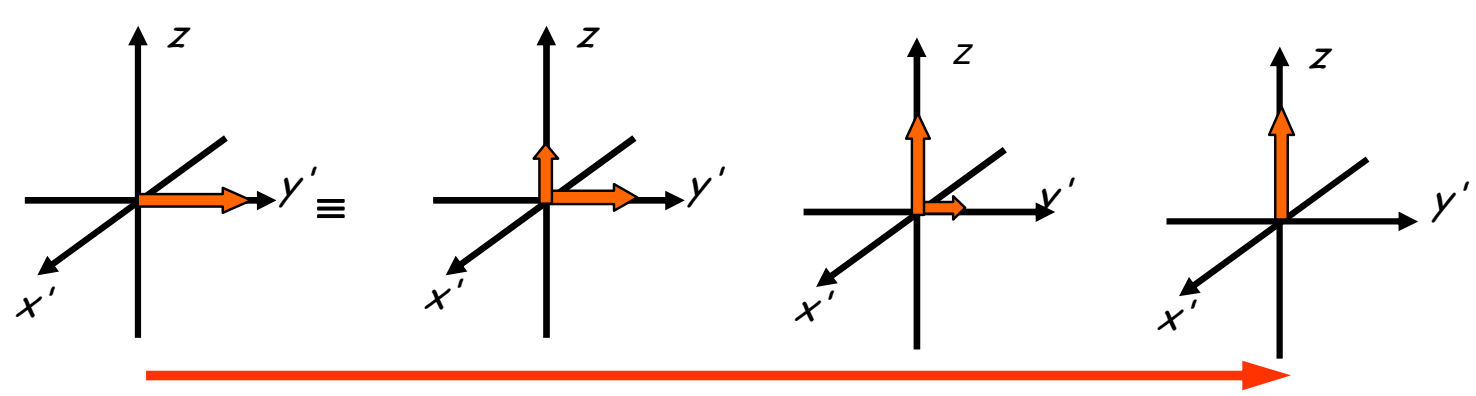

tempo

FIGURA 2.5 - Esquema vetorial do fenômeno da relaxação longitudinal . 


\subsubsection{Relaxação transversal}

Este processo de relaxação conhecido como relaxação transversal ou spinspin não está relacionado ao retorno da magnetização à condição de equilíbrio como no caso da longitudinal. Ele está relacionado com a perda de coerência da magnetização do plano xy devido à troca de energia entre os spins. Essa perda de coerência é atribuída a interações diretas entre os momentos magnéticos individuais, sem haver modificação na energia do sistema, causando um processo de relaxação conhecido como spin-spin ou relaxação transversal [4].

A magnetização induzida pelo pulso de rádio freqüência $(R F)$ será constituída por várias magnetizações, que irão precessionar com freqüências de Larmor diferentes no plano transversal. Conseqüentemente, a magnetização total tenderá a desaparecer ao longo do tempo devido ao espalhamento total dos spins no plano transversal, como mostrado na Figura 2.6.

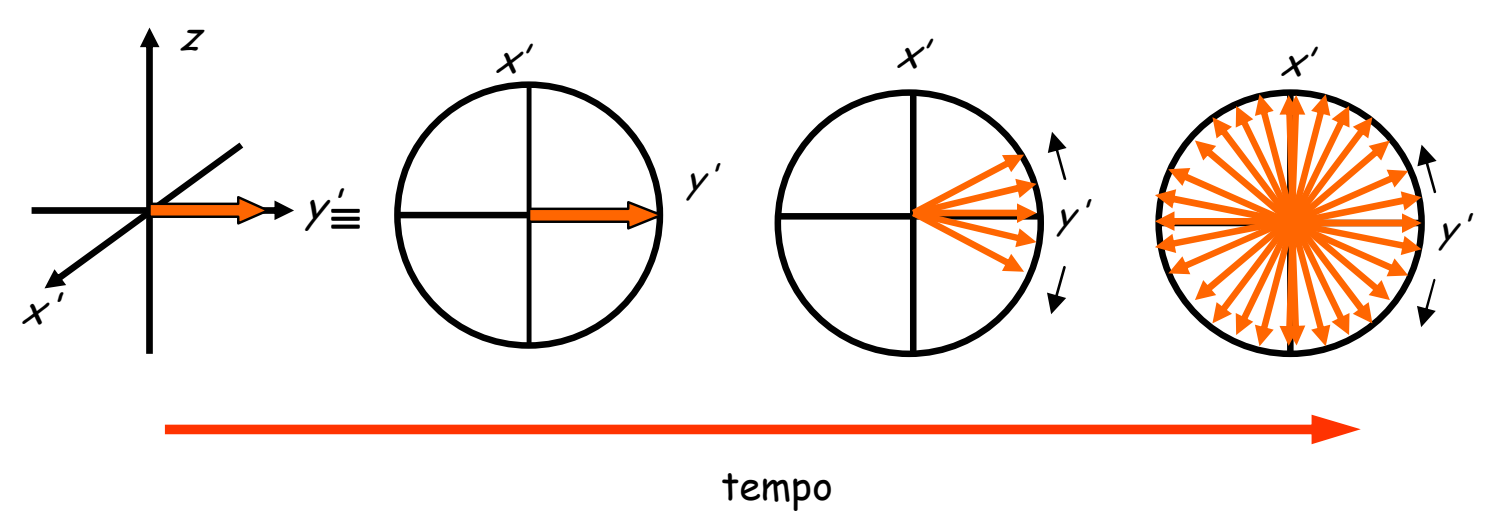

FIGURA 2.6 - Relaxação transversal. 
A relaxação transversal, caracterizada pela constante $T_{2}$, provoca um decaimento exponencial da magnetização transversal.

A não-homogeneidade do campo magnético, $\Delta \mathrm{B}_{0}$, também faz com que as componentes transversais da magnetização se dispersem no plano xy. Portanto, o decaimento da magnetização transversal observado num FID (Free Induction Decay) não retrata somente o tempo de relaxação spin-spin dado por $T_{2}$. Dessa forma, $a$ constante de tempo com a qual o FID decai é na verdade representada por um tempo de relaxação efetivo $\mathrm{T}_{2}{ }^{*}$.

A diminuição de $T_{2}{ }^{*}$ contribui para um decaimento mais rápido do sinal de RMN, causando o alargamento das linhas espectrais no domínio da freqüência. Para que isso não aconteça, têm-se buscado campos magnéticos cada vez mais homogêneos, onde $\mathrm{T}_{2}{ }^{*}$ se aproxime do valor de $\mathrm{T}_{2}$.

Os espectrômetros de RMN de baixa resolução em baixo campo são baseados em ímãs permanentes pouco homogêneos, não sendo possível a observação do deslocamento químico. A separação entre os compostos é baseada no tempo de relaxação longitudinal $\left(T_{1}\right)$ e transversal $\left(T_{2}\right)$.

Os tempos de relaxação são medidos com as técnicas denominadas CPMG (Carr-Purcell-Meiboom-Gill) e CWFP (Continuous Wave Free Precession).

\subsubsection{Seqüência de pulsos de CPMG (Carr-Purcell-Meiboom-Gil)}

Devido às dificuldades de se medir $\mathrm{T}_{2}$, houve a necessidade de desenvolver técnicas que permitissem minimizar ou anular os efeitos da não homogeneidade do campo $B_{0}$ no decaimento do sinal FID. A não homogeneidade do campo $B_{0}$ faz com que a magnetização individual dos spins sinta campos ligeiramente diferentes, 
causando assim uma perda mais rápida de coerência de fase, logo após o término do pulso quando acontece o processo de relaxação.

Para medir o tempo $T_{2}$ normalmente se utiliza uma técnica conhecida como eco de spin ou algumas de suas variações, tal como CPMG. Essa técnica apresenta um pulso de excitação de $90^{\circ}$ seguido de um trem de pulsos de leitura de $180^{\circ}$, sendo a mesma descrita da seguinte forma:

$$
\left[90^{\circ} \mathrm{x}^{\prime}-\tau-180^{\circ} \mathrm{x}^{\prime}-\tau-(\mathrm{eco})-\tau-180^{\circ} \mathrm{x}^{\prime}-\tau-(\mathrm{eco})-\tau-\ldots-180^{\circ} \mathrm{x}^{\prime}-\tau-\right.
$$

$(\mathrm{eco})-D] n$

onde $n$ representa o número de vezes que essa seqüência será repetida para que os dados sejam coletados, $\tau$ é o tempo de espera entre dois pulsos sucessivos e $D$ é o tempo necessário para que aproximadamente $99 \%$ dos spins retornem ao equilíbrio térmico (equivalente a $5 T_{1}$ ). A Figura 2.7 demonstra o funcionamento do método CPMG de acordo com a forma apresentada acima.

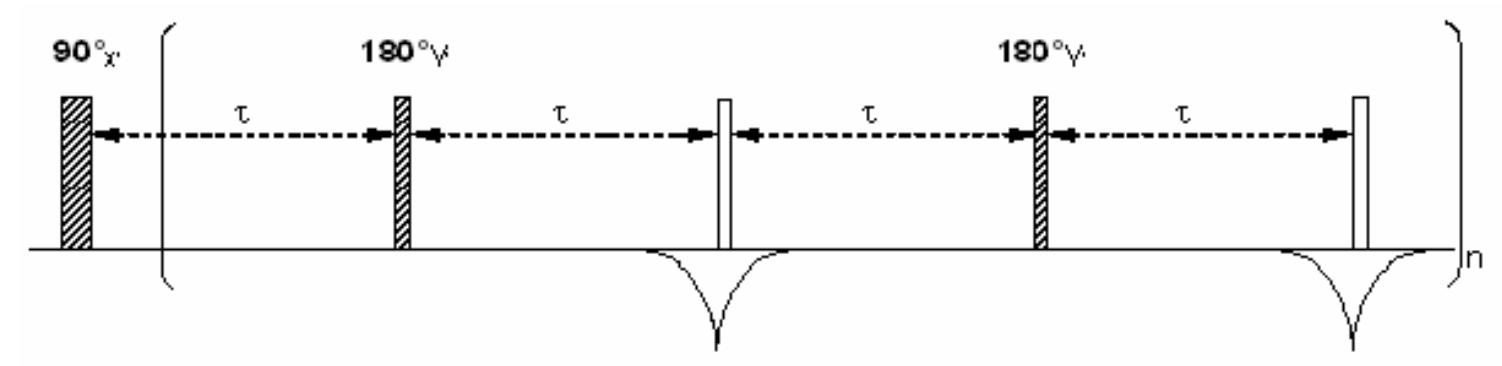

FIGURA 2.7 - Seqüência de pulsos do método de CPMG.

A intensidade do sinal de RMN da seqüência CPMG (eco) decai exponencialmente com a constante de tempo $T_{2}$. 


\subsubsection{Seqüência de pulsos de CWFP (Continuous Wave Free Precession)}

Recentemente foi desenvolvida uma nova técnica de RMN, baseada na técnica SSFP (Steady-State Free Precession), denominada "Continuous Wave Free Precession" (CWFP), que pode ser usada em várias análises físicas e químicas. Tal técnica tem sido usada para melhorar a relação sinal ruído em medidas quantitativas em aparelho de RMN de baixa resolução [5, 22], também para medidas rápidas e simultâneas dos tempos de relaxação $T_{1}$ e $T_{2}$.

A diferença entre as técnicas SSFP e CWFP pode ser observada devido à sobreposição do FID e do eco de spin apresentado pela técnica CWFP, uma vez que o tempo entre os pulsos na técnica de CWFP é muito curto em comparação aos valores comumente utilizados nas seqüências de SSFP; com isso, é possível somar vários espectros, o que faz aumentar a ralação sinal ruído. Na técnica SSFP, o FID e o eco de spin são apresentados separadamente.

A seqüência CWFP consiste de um trem de pulsos de rádio freqüência (RF) igualmente espaçados por um tempo $T_{p} \ll<T_{2}{ }^{*}$, onde $T_{p}$ é tempo do pulso e $T_{2}{ }^{*}$ é a constante de tempo de decaimento do sinal de RMN, considerando-se o efeito da não-homogeneidade do campo magnético. Para $T_{p}$ de $0,3 \mathrm{~ms}$, torna-se possível a aquisição de mais de 3000 espectros/segundos.

A Figura 2.8 apresenta um exemplo do ganho de sensibilidade da técnica CWFP em relação à medida de RMN convencional, baseada no FID para medidas do teor de óleo [14]. Nesse caso o ganho foi calculado em cerca de oito vezes. 


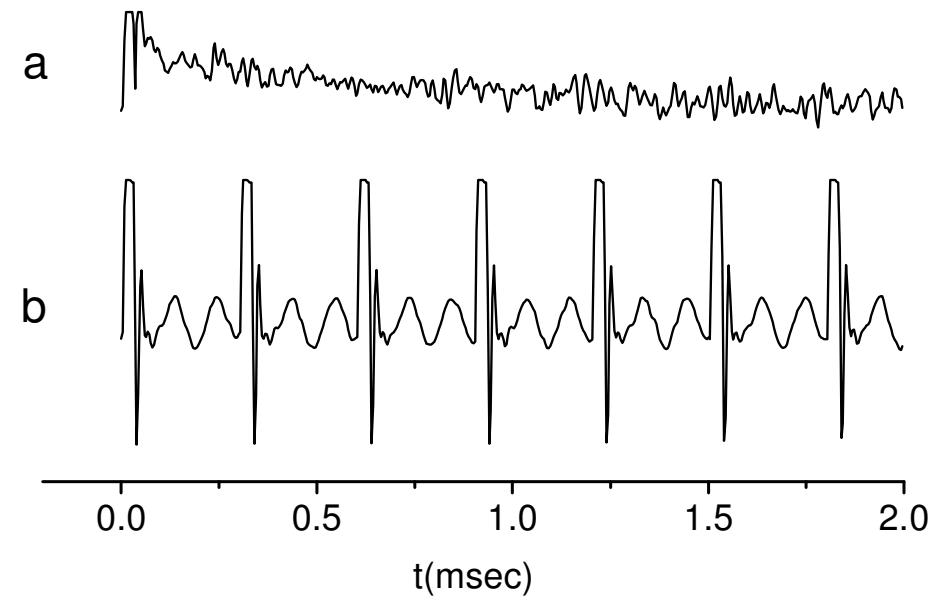

FIGURA 2.8 - Sinais de RMN de uma amostra de 2,2 mg de óleo vegetal obtidos com a técnica de análise do FID (a) e CWFP (b) em 1,38s.

A técnica de CWFP pode ser usada na medida rápida e simultânea dos tempos de relaxação $T_{1}$ e $T_{2}$ [22]. Pelo método convencional seriam necessárias a aplicação de dois experimentos distintos, inversão/recuperação e CPMG para obtenção dos mesmos.

A Figura 2.9 apresenta os três estágios resultantes do decaimento da magnetização do sinal gerado pelo CWFP, ou seja: (a) Regime de alternância de intensidade, representando a alternância da amplitude do sinal que possui a dependência com $\mathrm{T}_{\mathrm{p}} / \mathrm{T}_{2}{ }^{*}$; (b) Estado quase-estacionário; e (c) Estado verdadeiramente-estacionário, apresentando uma dependência com $T_{1}$ e $T_{2}$. 


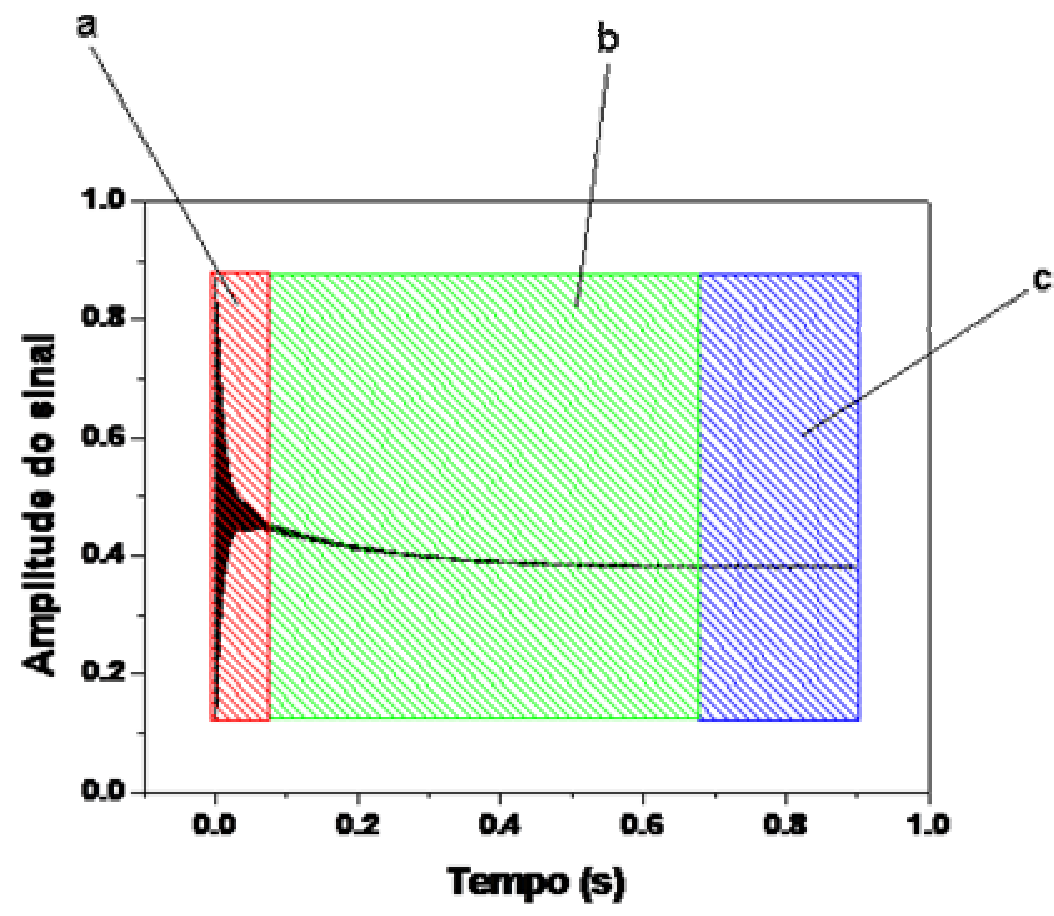

FIGURA 2.9 - Representação do sinal do CWFP para amostra de ácido fosfórico $\left({ }^{1} \mathrm{H}\right)$ com $T_{1}=190 \mathrm{~ms}$ e $T_{2}=140 \mathrm{~ms}$. (a) Regime de alternância de intensidade, (b) Estado quaseestacionário e (c) Estado verdadeiramente-estacionário.

\subsection{Transformação do músculo em carne}

O músculo é constituído por uma unidade estrutural, a fibra, e por uma unidade funcional, o sarcômero. Existem três tipos básicos de músculos, os estriados esqueléticos, os estriados cardíacos e os voluntários viscerais. Além disso, o músculo esquelético de mamíferos é constituído por 65 a 80\% de água, 16 a $22 \%$ de proteínas, 1 a $2 \%$ de carboidratos, 1 a $13 \%$ de gorduras e $1 \%$ de outros materiais solúveis [17,29]. A Figura 2.10 representa um esquema com a constituição de um músculo. 


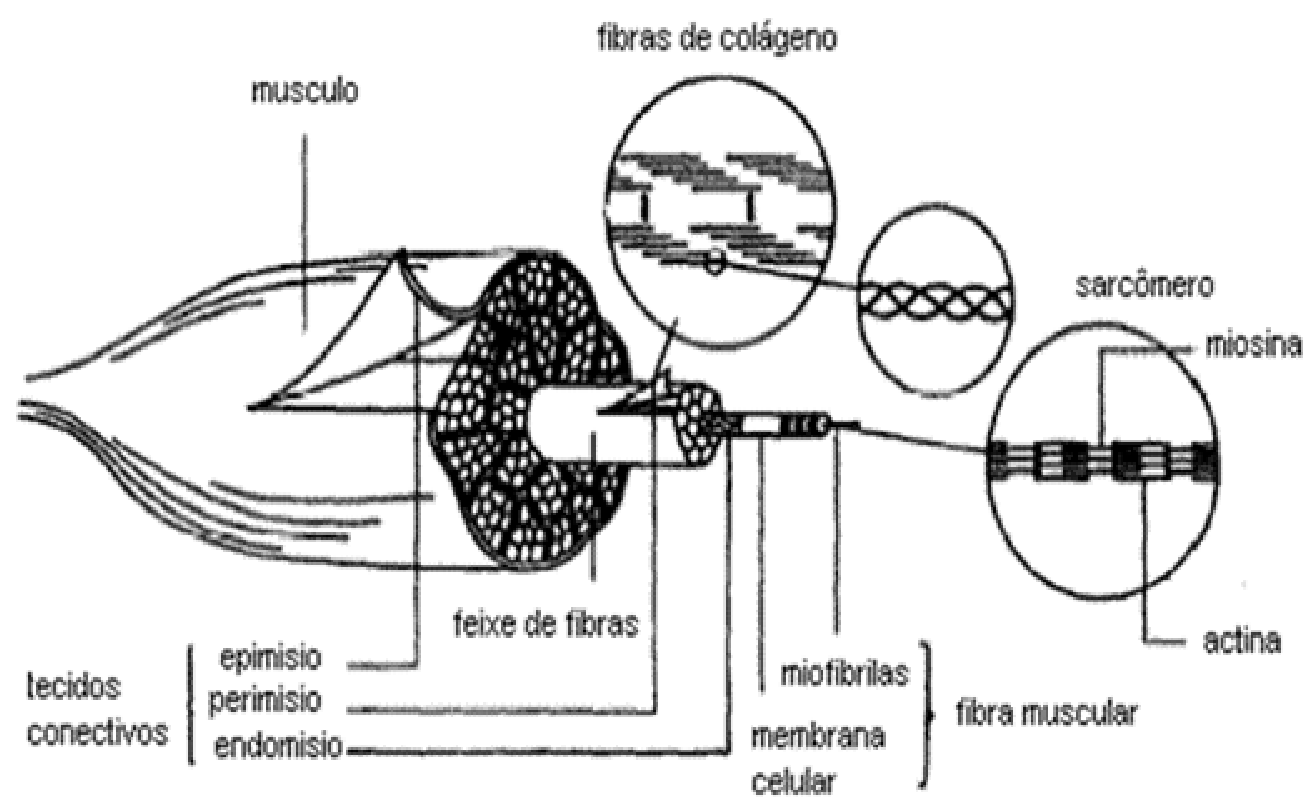

FIGURA 2.10 - Representação da estrutura muscular macroscópica.

O músculo é envolvido por um tecido conjuntivo chamado epimísio, que tem a função de unir o músculo aos pontos de origem e inserção, formando, em muitos casos, os tendões dos músculos. A membrana celular, chamada sarcolema, é envolvida por outro tipo de tecido conectivo chamado endomísio. As fibras são reunidas em feixes de fibra, onde o terceiro tipo de tecido, o perimísio, recobre as fibras musculares individualmente [17].

Dentro da fibra muscular, os menores elementos contráteis (sarcômeros) são arranjados numa longa linha, uma miofibrila de $1 \mu \mathrm{m}$ de diâmetro. $\mathrm{O}$ fluido que envolve esta, o sarcoplasma, contém proteínas, incluindo as enzimas glicolíticas e proteolíticas, além de todos os elementos usualmente encontrados na célula, como mitocôndria, ribossomos etc. 
O grande mérito nutricional da carne é a quantidade e a qualidade dos aminoácidos constituintes dos músculos, dos ácidos graxos essenciais e das vitaminas do complexo B presentes, tendo também importância o teor de ferro.

O músculo, após o abate, passa por vários processos físico-químicos até se transformar em carne. Os conhecimentos dos processos, da estrutura do músculo e da carne são fundamentais para a compreensão dessa conversão e, conseqüentemente, da qualidade da carne como alimento.

Com a morte e, por conseqüência, com a falência sangüínea, o aporte de oxigênio e o controle nervoso deixam de chegar à musculatura, com isso, o músculo passa a utilizar a via anaeróbica, para obter energia para um processo contrátil desorganizado. Nesse processo há transformação de glicogênio em glicose, e como a glicólise é anaeróbica, gera lactato e verifica-se a queda do pH [28].

Com o consumo das fontes energéticas, o processo contrátil tende a cessar formando um complexo irreversível denominado de acto-miosina. A formação desse complexo resulta numa condição de rigidez e essa é a forma como as proteínas miofibrilares são encontradas após a morte. Nesse estado, a musculatura atinge o rigor mortis, ou seja, os músculos transformam-se em carne [28]. Um dos aspectos mais marcantes da transformação do músculo em carne é a queda do pH, inclusive, a ponto de determinar a futura qualidade da carne. 


\subsection{Aplicações de ressonância magnética no controle de qualidade de carnes}

A utilização de ressonância magnética nuclear no controle de qualidade de alimentos vem ganhando espaço por ser uma técnica rápida e não destrutiva. Algumas análises quantitativas começaram na década de 60 , como a análise de óleo em sementes e medidas de relaxação de RMN de baixo campo para o estudo da água no tecido muscular.

Entre outros exemplos, a RMN vem sendo atualmente utilizada na indústria de alimentos na determinação do teor de gordura sólida (que são utilizados nas indústrias de chocolate e de manteiga), na determinação do teor de água e óleo em alimentos fritos, no estudo de frutas e vegetais, na caracterização da estrutura muscular da carne bovina, no controle de qualidade da cerveja, etc [6].

No campo da ciência da carne, podem-se utilizar as medidas de RMN na determinação da distribuição de gordura intramolecular e na mudança de distribuição da água no músculo pós-morte.

Bertram et al. em [7] utilizaram as medidas de RMN de baixo campo com a técnica de CPMG em músculos durante o período de 15 minutos, 85 minutos e depois de 24 horas pós-morte a fim de observar a mudança de distribuição da água no músculo de suínos, sendo estes animais expostos a dois níveis de estresse antes do abate. O músculo esquelético é constituído de aproximadamente de 70 a $75 \%$ de água e as propriedades físicas da mesma são importantes para a sobrevivência e funcionalidade do músculo vivo, no processo pós-morte e no desenvolvimento da qualidade da carne. 
Para analisar os dados da técnica de CPMG foram utilizadas Análises de Componentes Principais (PCA) que é um método descritivo e Regressão Parcial dos Mínimos Quadrados (PLSR), sendo esta uma das técnicas de calibração multivariadas.

Bertram et al. em [32] analisaram os efeitos da qualidade de carne fresca, da temperatura de congelamento $\left(-20{ }^{\circ} \mathrm{C}\right.$ até $\left.-80 \stackrel{\circ}{ } \mathrm{C}\right)$ e a duração da estocagem no freezer na mudança e distribuição da mobilidade da água da carne suína com pH normal e $\mathrm{pH}$ alto, usando relaxometria de $\mathrm{T}_{2}$ em $\mathrm{RMN}$ de baixo campo. As medidas foram realizadas em um total de 10 amostras para cada uma das duas qualidades em cada mês. A relaxação transversal, $T_{2}$, foi medida usando a seqüência de pulsos de CPMG.

Sorland et al. em [33] utilizaram RMN de baixo campo para medidas de teor de gordura e a retenção de água usando como amostras pedaços de carnes bovina e suína. Apesar das inovações na análise de alimentos, a indústria de alimentos se beneficia com o desenvolvimento de métodos rápidos. A RMN de baixo campo é um método rápido que determina o conteúdo de água e de gordura simultaneamente. Neste caso foi utilizada a seqüência de pulsos de CPMG para medir o teor de gordura e o conteúdo de água.

Bertram et al. [34] usaram a RMN de baixo campo para estudar a relação entre a temperatura de cozimento, distribuição de água e atributos sensoriais. Eles observaram que as medidas de $T_{2}$, medido pela seqüência de pulsos de CPMG, estão altamente correlacionadas com atributos sensoriais de carne suína cozida nas temperaturas de $62 \mathrm{e} 75^{\circ} \mathrm{C}$. O estudo também demonstrou que a maior suculência e maciez é obtida em $75^{\circ} \mathrm{C}$ do que em $62^{\circ} \mathrm{C}$. Os dados foram analisados por Regressão Parcial dos Mínimos Quadrados (PLSR). 
Bertram et al. [35] realizaram um estudo combinando a espectroscopia de infravermelho com transformada de Fourier e medida de $T_{2}$ por RMN em baixo campo utilizando como amostras carne suína com pH normal e pH alto, para caracterização da mudança das estruturas das proteínas miofibrilares e propriedades físico-químicas, durante o cozimento de $28{ }^{\circ} \mathrm{C}$ a $81 \stackrel{\circ}{\circ} \mathrm{C}$. Foram observadas mudanças pronunciadas na propriedade da água e na organização estrutural das proteínas durante o cozimento. Para medir o tempo de relaxação transversal $T_{2}$ foi utilizada a seqüência de pulsos de CPMG. Para estimar uma correlação entre variáveis de temperatura e qualidade da carne, absorbância de infravermelho com transformada de Fourier e as variáveis obtidas pela espectroscopia de RMN foi usada Regressão Parcial dos Mínimos Quadrados (PLSR).

Bertram et al. [36] estudaram a combinação entre medidas de RMN em baixo campo $\left(T_{2}\right)$ com medidas simultâneas de Differential Scanning Calorimetry (DSC). Foram estudadas as relações entre as mudanças de características da água durante o cozimento, utilizando como amostras carne de suínos pré-aquecidos em várias temperaturas entre 25 e $75^{\circ} \mathrm{C}$, de forma a obter um melhor entendimento da relação entre o aquecimento e a desnaturação das proteínas e a associação com as propriedades da água na carne. A relaxação transversal $T_{2}$ foi medida usando a seqüência de pulsos de CPMG. Para a análise dos dados de RMN e DSC foram utilizados utilizadas Análises de Componentes Principais (PCA) e Regressão Parcial dos Mínimos Quadrados (PLSR).

Brondum et al. [37] compararam as diferenças entre as técnicas de espectroscopia para medidas online visando predizer os parâmetros da capacidade de retenção de água e composição química (conteúdo de água e gordura) na carne 
de porco. As técnicas de espectroscopia selecionadas para este estudo foram um probe de fibra óptica (FOP), um visível (VIS), espectroscopia de reflectância de infravermelho próximo (NIR), espectroscopia de fluorescência e RMN de baixo campo. As análises foram realizadas em dois músculos dos suínos (longissinus dorsi e semitendinosous). A relaxação transversal $T_{2}$ foi medida usando a seqüência de pulsos de CPMG e a relaxação longitudinal $T_{1}$ foi medida usando a seqüência e inversão/recuperação. Os dados obtidos pelos espectrômetros foram processados usando análises multivariadas, Regressão Parcial dos Mínimos Quadrados (PLSR), com a finalidade de desenvolver a calibração dos modelos para predizer as informações referentes à capacidade de retenção da água e a composição química da carne. 


\section{Aspectos de Redes Neurais}

Redes neurais artificiais são modelos matemático-computacionais inspirados no comportamento humano, mais especificamente no cérebro. O cérebro possui um sistema de processamento de informações altamente complexo, não linear e paralelo. Redes neurais possuem um processamento paralelamente distribuído constituído de unidades de processamento simples, que têm a propensão natural de armazenar conhecimento experimental e posteriormente torná-lo disponível para o uso [9].

Semelhanças entre o cérebro e as redes neurais podem ser observadas devido ao processo de aprendizagem e pela utilização de pesos sinápticos. O processo de aprendizagem é responsável pelo conhecimento adquirido pela rede. Isso acontece porque são extraídas as características necessárias do conjunto de dados apresentados à rede. Os pesos sinápticos são usados como armazenamento do conhecimento adquirido.

As principais vantagens da rede neural podem ser definidas como: capacidade de aprender através de exemplos e de generalizar as informações aprendidas. Generalização está relacionada com a capacidade da rede aprender com um conjunto reduzido de exemplos e posteriormente dar uma resposta coerente para dados não-conhecidos. 
O primeiro modelo de rede neural foi criado por Warren McCulloch e Walter Pitts em 1943. O neurônio artificial desenvolvido por eles tinha uma única saída, e essa saída era uma função binária (threshold) da soma dos valores de entrada.

Levou-se algum tempo para que o aprendizado da rede neural virasse objeto de estudo de outros pesquisadores e, em 1958, Frank Rosenblatt demonstrou o seu novo modelo chamado perceptron. Esse modelo possui três camadas: a primeira camada recebe os dados de entradas exteriores, possuindo conexões fixas (retina); a segunda camada recebe impulsos da primeira através de conexões cuja eficiência de transmissão (peso) é ajustável, que por sua vez, envia saídas para a terceira camada, onde será apresentada a resposta [10].

Em 1969, Minsky e Papert demonstraram que o perceptron não era capaz de resolver algumas tarefas [9]. Essa rede apenas resolvia problemas linearmente separáveis. Tal descoberta fez o número de pesquisadores que trabalhavam no desenvolvimento de redes neurais se reduzir e, por alguns anos, o tema ficou adormecido; porém, poucos pesquisadores ainda continuaram trabalhando na área.

Em 1982, John Hopfield publicou um artigo que foi responsável pela retomada das pesquisas na área de redes neurais. Ele mostrou a relação entre redes recorrentes auto-associativas e sistemas físicos. Depois disso, abriu-se caminho para outras pesquisas, como a do desenvolvimento do algoritmo backpropagation. 


\subsection{Modelo de Neurônio biológico e modelo de neurônio artificial}

O sistema nervoso humano é formado por células nervosas denominadas neurônios, que são divididos em três seções: o corpo celular, os dendritos e o axônio. O corpo celular, também conhecido como soma, medindo milésimos de milímetros é o centro dos processos metabólicos da célula nervosa, a partir do qual, projetam-se extensões filamentares, como os dendritos e os axônios.

Os dendritos têm volumes muitas vezes maiores do que o próprio corpo celular, e formam uma árvore dendrital. Eles são responsáveis pelo recebimento das informações ou impulsos nervosos de outros neurônios e de conduzi-los das extremidades para o corpo celular. O corpo celular processa os sinais recebidos pelos dendritos e libera novos impulsos, que serão transmitidos para a extremidade da célula através dos axônios. Os axônios podem ser definidos como dispositivos de saídas.

A célula controla a produção de impulsos elétricos através de um processo denominado função limiar. Somente será produzida uma saída se a soma das entradas for maior ou igual a um determinado limiar.

As extremidades do axônio são conectadas com os dendritos de outros neurônios pelas sinapses, permitindo assim a propagação dos impulsos nervosos de uma célula para outra. Com a união desses nodos é formada a rede neural.

A Figura 3.1 ilustra de forma simplificada um neurônio biológico. 


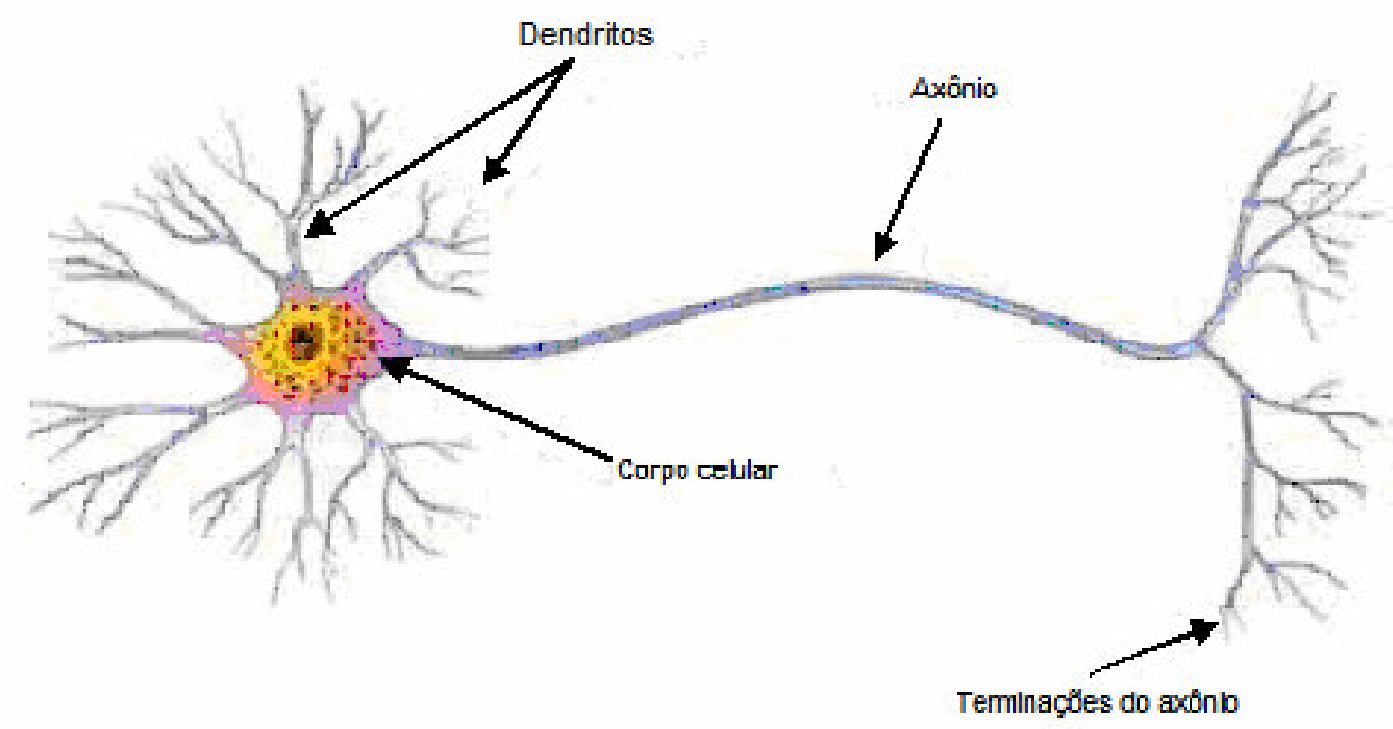

FIGURA 3.1 - Representação de um neurônio biológico.

O primeiro neurônio artificial foi criado por McCulloch e Pitts e sua descrição baseia-se em $m$ terminais de entrada $x_{1}, x_{2}, \ldots, x_{m}$, onde as características dos padrões são apresentadas à rede. Esses terminais de entrada são acoplados a pesos $w_{k 1}, w_{k 2}, \ldots, w_{k m}$, cujos valores podem ser positivos ou negativos. Tais valores estão relacionados com os tipos de sinapses utilizadas pela rede. Se for utilizada uma sinapse inibitória, as trocas de informações entre os neurônios serão dificultadas ou impedidas. Já na sinapse excitatória, as passagens de informações entre os neurônios são permitidas.

Depois de efetuada a multiplicação entre os terminais de entrada e os pesos, $x_{i} w_{i}$, o corpo celular faz a soma ponderada dos valores recebidos $x_{i} w_{i}$ e decide se 0 neurônio deve ou não disparar. É aplicada uma função de ativação, que ativa ou não a saída do neurônio, dependendo do valor da soma ponderada das suas entradas. A saída do neurônio poderá ser linear ou não-linear de acordo com a função de ativação utilizada. 
Dentre as funções de ativação mais usadas estão as funções rampa, degrau, degrau bipolar, sigmóide, tangente hiperbólica, entre outras. O neurônio terá sua saída ativada quando:

$$
\sum_{i=0}^{m} x_{\mathrm{i}} w_{i} \geq \theta
$$

onde:

- $\quad m \rightarrow$ Número de neurônios.

- $x_{1} \rightarrow$ Entrada da rede.

- $\quad w_{i} \rightarrow$ Peso associado à entrada $x_{1}$.

- $\quad \theta \rightarrow$ Limiar de excitação (threshold) do neurônio.

O modelo de neurônio proposto por McCulloch e Pitts apresenta apenas um terminal de saída $y$, onde o resultado final é concluído e apresentado [10]. A Figura 3.2 apresenta o neurônio artificial idealizado por McCulloch e Pitts. Os neurônios artificiais procuram simular o funcionamento dos neurônios biológicos e, para que isso aconteça, utilizam-se pesos sinápticos. Isso faz com que as conexões dos neurônios artificiais se comportem como as conexões dos neurônios biológicos.

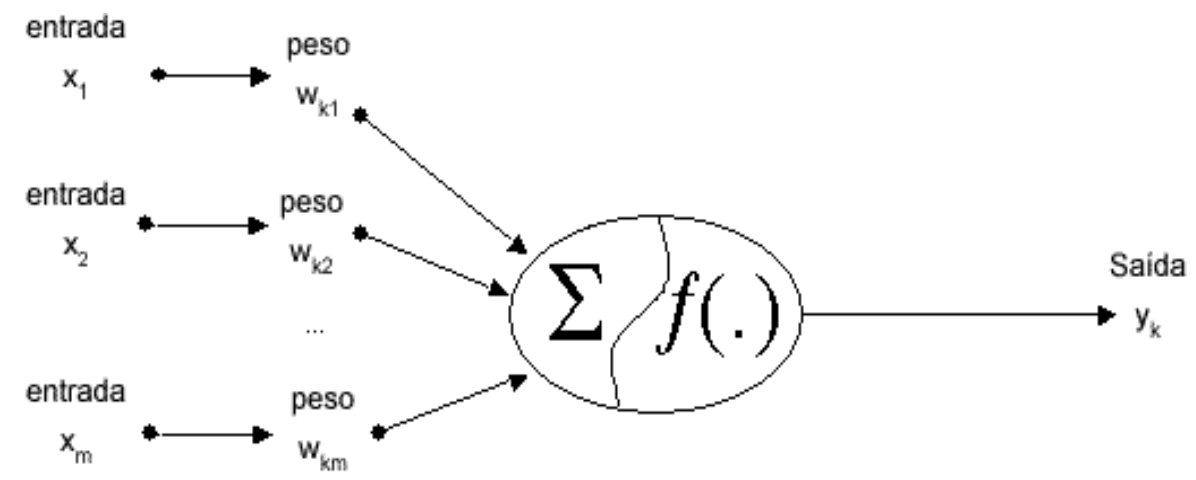

FIGURA 3.2 - Representação de um neurônio artificial. 
A Figura 3.3 ilustra algumas das funções de ativação mais utilizadas.

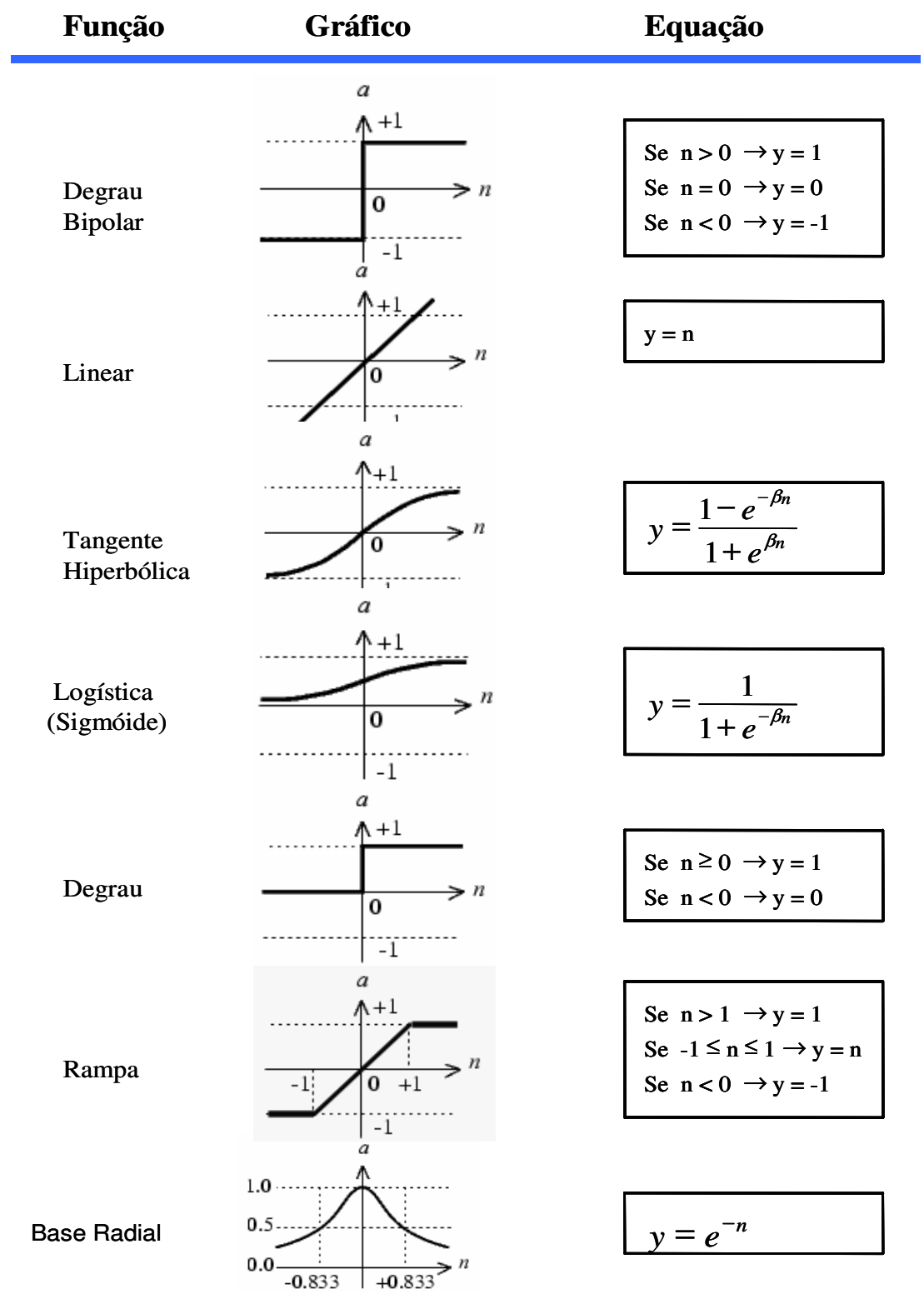

FIGURA 3.3 - Funções de ativação e suas equações.

A Figura 3.4 apresenta de uma forma simplificada a comparação do neurônio biológico com o neurônio artificial. 


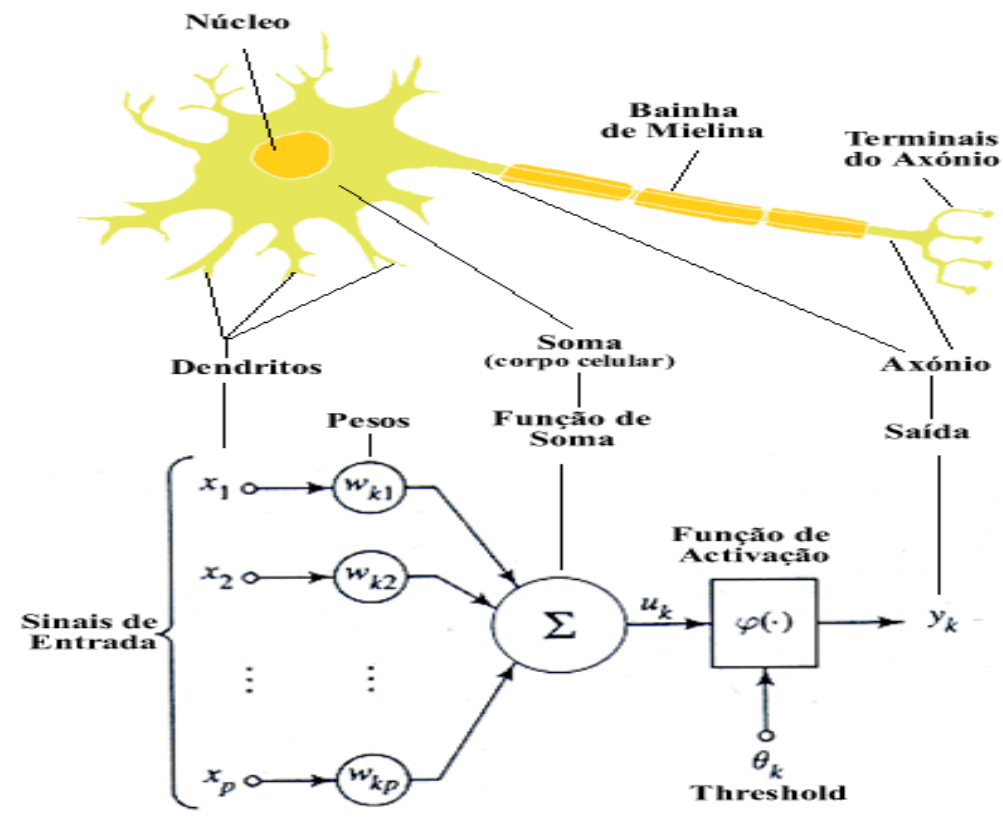

FIGURA 3.4 - Comparação entre o neurônio biológico e o artificial.

O modelo do neurônio criado por McCulloch e Pitts foi simplificado, isto é, os neurônios em cada camada da rede disparam sincronamente, sendo avaliados ao mesmo tempo. No sistema biológico não existe um mecanismo que sincronize as ações dos neurônios, como também não há restrição quanto a ativação da saída em tempos discretos como no modelo de McCulloch e Pitts [10].

\subsection{Arquitetura de redes neurais artificiais}

As arquiteturas das redes neurais artificiais são definidas por parâmetros, tais como número de camadas da rede, número de neurônios em cada camada, tipo de conexão entre os neurônios e topologia da rede.

A maneira como o neurônio da rede neural é estruturado está intimamente relacionado com o algoritmo de aprendizado usado para treinar a rede [9]. 
Existem três classes diferentes de arquiteturas. Essas classes determinam o tipo de problema que podem ser tratados pela rede neural.

\subsubsection{Feedforward de única camada}

Rede feedforward (alimentação para frente) ou acíclica de única camada é constituída de apenas uma camada de entrada e uma camada de saída.

Os neurônios da camada de entrada correspondem aos neurônios sensoriais ou lineares que recebem os sinais da rede. Os dados não são processados na camada de entrada, eles são projetados para a camada de saída. A camada de saída é responsável pelo processamento e apresentação dos resultados finais.

A Figura 3.5 ilustra uma rede feedforward, com $m$ neurônios na camada de entrada e quatro neurônios na camada de saída.

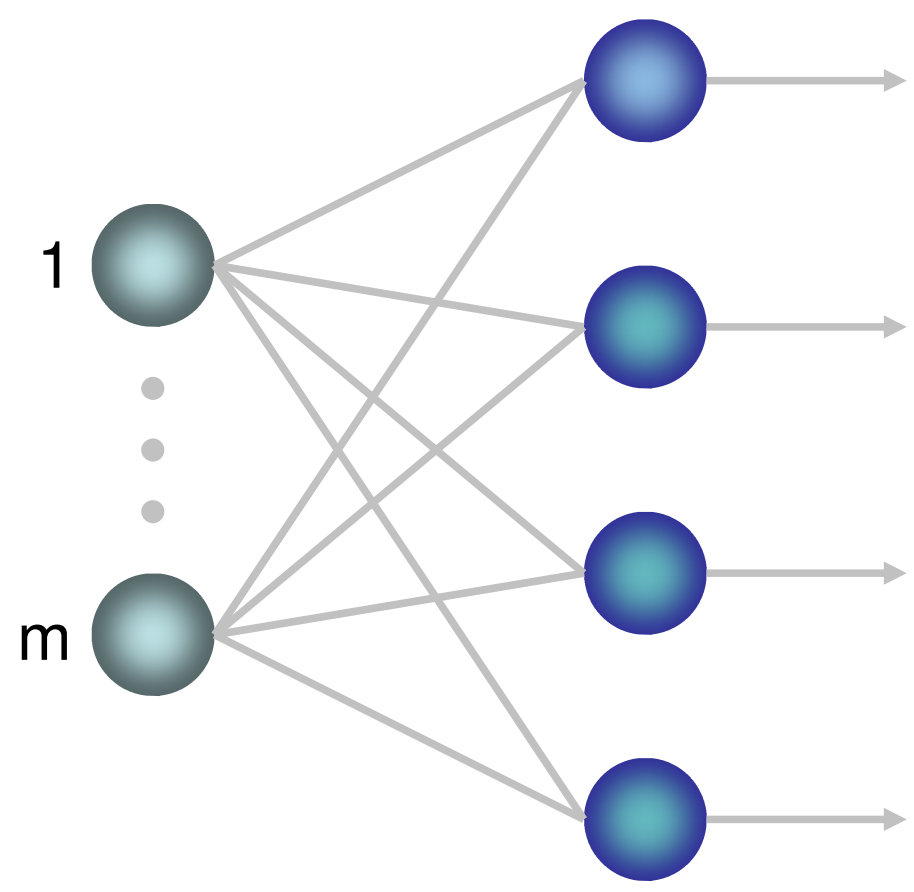

FIGURA 3.5 - Rede feedforward ou acíclica de única camada. 


\subsubsection{Feedforward de múltiplas camadas}

Essa rede se distingue da primeira por apresentar uma ou mais camadas intermediárias ou escondidas. A utilização de uma camada intermediária não-linear faz aumentar a capacidade de processamento da rede.

A função da camada intermediária é fazer o processamento baseado em conexões ponderadas, podendo ser consideradas extratoras de características.

O sinal apresentado na camada de entrada é projetado junto com elementos do padrão de ativação na camada intermediária (segunda camada da rede), onde os dados serão processados e o resultado será usado como atributo de entrada para a camada de saída da rede.

A Figura 3.6 ilustra uma rede Feedforward de múltiplas camadas, com $m$ neurônios na camada de entrada, quatro neurônios na camada intermediária e dois neurônios na camada de saída.

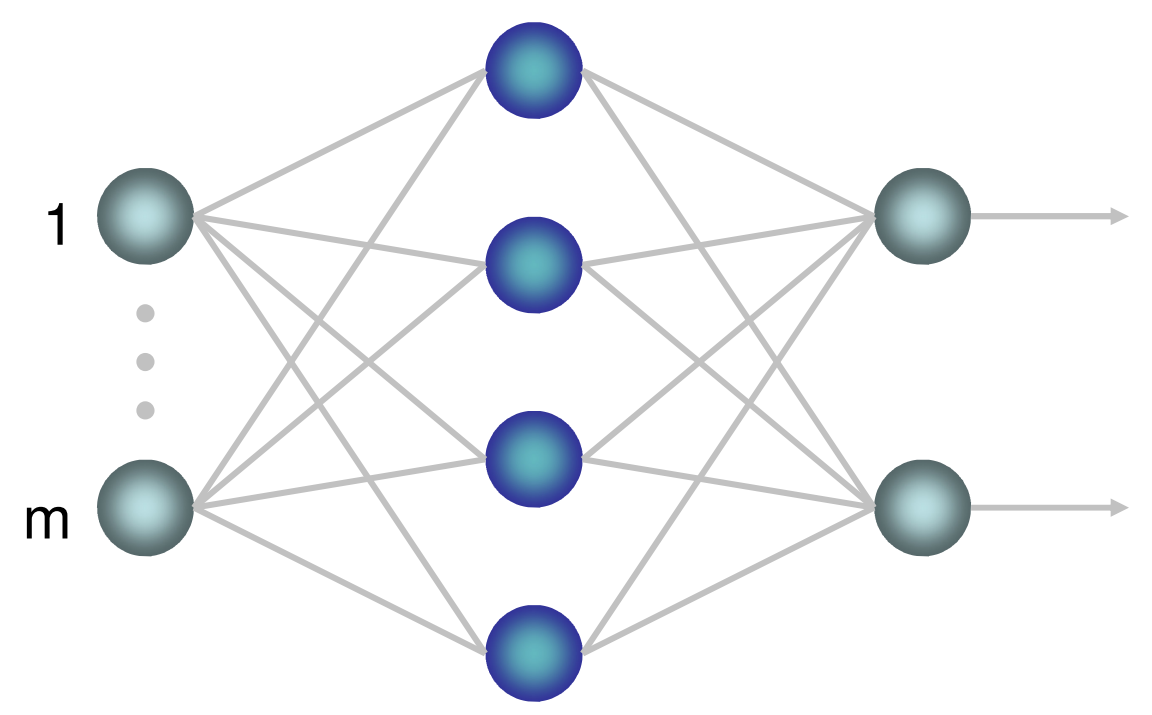

FIGURA 3.6 - Rede feedforward ou acíclica com uma camada intermediária e uma camada de saída. 


\subsubsection{Redes recorrentes}

As redes recorrentes se distinguem das redes feedforward por ter no mínimo uma realimentação. Isso significa que os sinais de saída dos neurônios serão usados como entrada para os demais neurônios. A Figura 3.7 ilustra uma rede recorrente de uma única camada de neurônios. A partir dos próprios neurônios saem os sinais de saída, que serão utilizados como alimentação de entrada para todos os outros neurônios.

A realimentação na estrutura da rede recorrente tem interferência na capacidade de aprendizado da rede e em sua performance. Além disso, envolve o uso do elemento de atraso da unidade simbolizada por $Z^{-1}$, assumindo que a rede neural contém unidades não-lineares.

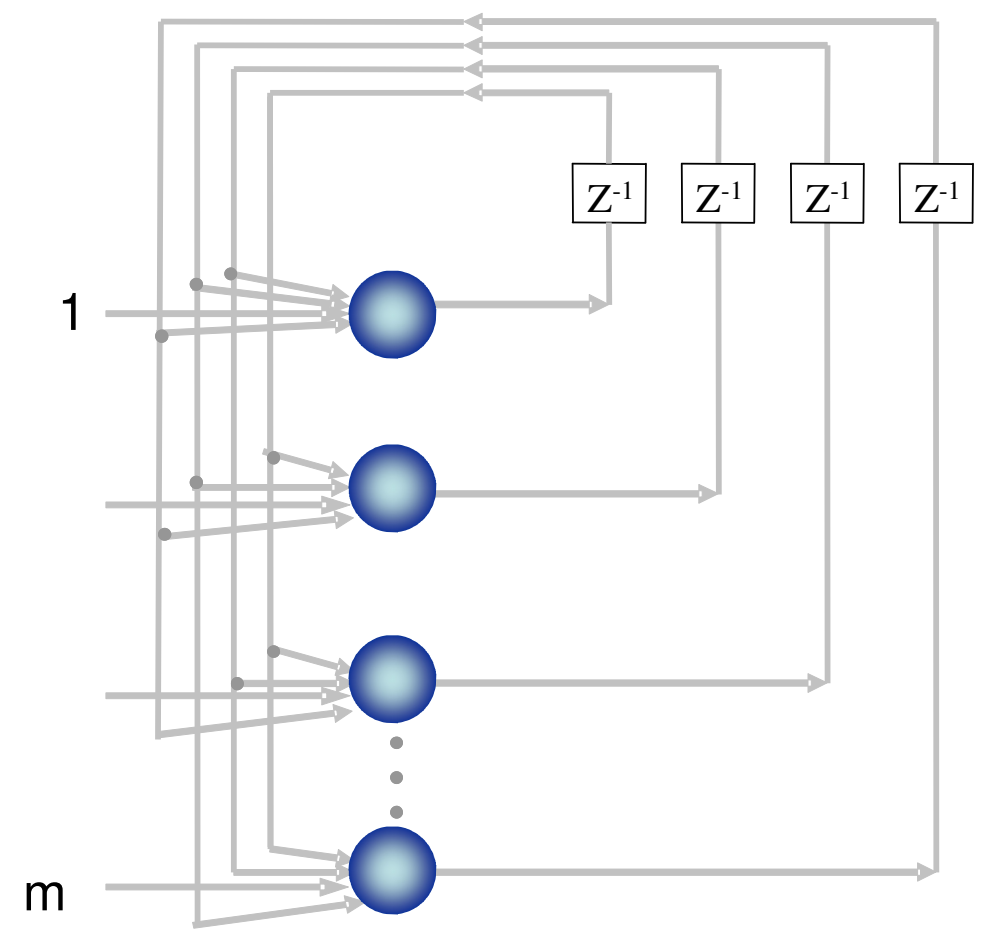

FIGURA 3.7 - Rede recorrente com realimentação. 


\subsection{Rede Perceptron Multicamadas}

A rede perceptron multicamadas (Multilayer Perceptron - MLP) é constituída de uma camada de entrada, uma ou mais camadas escondidas ou intermediárias e uma camada de saída. A camada intermediária tem a capacidade de detectar características dos padrões de entrada e utilizá-los para definir os valores de saída da rede. A camada intermediária aumenta o poder computacional da rede. De acordo com o número de camadas intermediárias, a rede MLP tem a capacidade de resolver problemas de classificação de padrões não linearmente separáveis ou aproximar qualquer outro tipo de função.

O processo de treinamento da MLP é o algoritmo back-propagation, que também pode ser conhecido como regra delta generalizada. Esse algoritmo é uma regra de aprendizado supervisionado. Durante o treinamento o erro é propagado de trás para frente na rede, daí a origem do nome back-propagation (retropropagação), sendo baseado na regra de aprendizado com correção do erro.

O aprendizado back-propagation constitui-se de dois passos principais: No primeiro passo (forward), um padrão de entrada é apresentado à rede e as informações são propagadas camada a camada até as suas saídas, produzindo uma resposta atual da rede. Durante essa fase os pesos sinápticos da rede permanecem fixos. No segundo passo (backward), a resposta atual produzida pela rede é subtraída da desejada, produzindo assim um sinal de erro. Esse sinal de erro é apresentado na camada de saída e será propagado de volta, camada a camada até as suas entradas. Durante essa fase os pesos sinápticos da rede são ajustáveis, de acordo com a regra de correção de erro.

O sinal de erro na saída do neurônio é calculado pela Equação (3.2). 


$$
e_{m}(n)=d_{m}(n)-y_{m}(n)
$$

onde:

- $e_{m} \rightarrow$ Sinal de erro na saída do neurônio $m$ em relação à $n$-ésima iteração.

- $\quad d_{m} \rightarrow$ Resposta desejada na saída do neurônio $m$.

- $y_{m} \rightarrow$ Resposta produzida na saída do neurônio $m$.

O valor instantâneo é a somatória do erro quadrático sobre todos os neurônios na camada de saída, e pode ser calculado diretamente conforme a Equação 3.3.

$$
E(n)=\frac{1}{2} \sum_{j \in C} e_{m}^{2}(n)
$$

onde:

- $\quad E(n) \rightarrow$ Soma instantânea do erro quadrático na iteração $n$.

- $\quad C \rightarrow$ Refere-se a todos os neurônios da camada de saída da rede.

E o erro quadrático médio é obtido pela somatória do erro quadrático, ou seja.

$$
E_{M}=\frac{1}{P} \sum_{n=1}^{P} E(n)
$$

onde:

- $\quad E_{M} \rightarrow$ Erro quadrático médio.

- $\quad P \rightarrow$ Número total de padrões.

O erro instantâneo e, conseqüentemente, o erro quadrático médio, é uma função de todos os parâmetros livres da rede, relativos aos pesos sinápticos e aos 
seus limiares. O objetivo do processo de treinamento é ajustar os parâmetros livres da rede e minimizar o erro quadrático médio [9].

O número de vezes que a rede repete o seu treinamento, efetuando a correção de seus pesos, é denominado de época. E o ajuste dos pesos é feito de acordo com o respectivo erro calculado para cada padrão apresentado à rede [9].

A rede MLP possui funções de ativação não-lineares e diferenciáveis, para que possa ser calculado o gradiente e com isso fazer o ajuste dos pesos sinápticos. A função de ativação mais utilizada em rede PMC é a logística, demonstrada pela Equação (3.5) [10].

$$
y_{i}=\frac{1}{1+e^{-\beta n}}
$$

onde:

- $\quad y_{i} \rightarrow$ Saída do neurônio.

- $\quad \beta n \rightarrow$ Campo local induzido (i.e., soma de todas entradas multiplicadas pelos pesos sinápticos, adicionada ao bias).

Para facilitar o treinamento da MLP é comum aumentar o número de camadas intermediárias, mas deve-se tomar cuidado quanto a esse aumento, pois o erro medido durante o treinamento se torna menos preciso conforme ele vai sendo retropropagado. Isso acontece porque toda vez que o erro é retropropagado é feita a sua estimativa.

Pode-se aumentar a capacidade de mapeamento não-linear da rede, aumentando-se o número de neurônios nas camadas intermediárias. Entretanto, se o número de neurônios for muito grande, o modelo pode se sobre ajustar na presença de ruídos da amostra de treinamento, memorizando os padrões de treinamento ao invés de extrair as características. Esse efeito é conhecido como 
overfitting. Mas se o número de neurônios na camada intermediária for pequeno, a rede pode não ser capaz de realizar o mapeamento desejado, pois sobrecarrega os neurônios que estão sendo utilizados e, conseqüentemente, a rede não converge. Esse efeito é conhecido como underfitting.

\subsection{Treinamento de redes Perceptron Multicamadas}

O tipo de aprendizado utilizado pela MLP é chamado de aprendizado supervisionado, pois as entradas e saídas da rede são fornecidas a partir de observações (medidas) efetuadas no processo.

São apresentados à rede sucessivos padrões de entrada e seus respectivos padrões de saída. Durante este processo, a rede realiza a atualização dos pesos de suas conexões, de acordo com uma determinada regra de aprendizagem. Isso acontece até que o erro entre os padrões de saída gerados pela rede alcance um valor mínimo desejado.

O aprendizado do tipo supervisionado pode ser classificado como estático e dinâmico. Os algoritmos estáticos não alteram a estrutura da rede, variando apenas os seus pesos. Os algoritmos dinâmicos alteram sua estrutura aumentando ou diminuindo o tamanho da rede [10].

O algoritmo utilizado para treinar redes do tipo MLP é o back-propagation, sendo o mesmo composto de duas fases. Essas fases são chamadas de forward e backward. Na primeira fase (forward), um padrão é apresentado às unidades da camada de entrada, o estímulo fornecido por essa camada é propagado camada por camada, até que a resposta seja produzida pela camada de saída. Como os valores 
de saídas desejados são conhecidos é então possível estimar os erros na camada de saída.

Na segunda fase (backward), a saída obtida pela rede é comparada à saída desejada dos padrões apresentados. Se as saídas forem diferentes, o erro é então calculado. A estimativa do erro é usada como referência para a correção dos pesos. A propagação acontece da camada de saída até a camada de entrada, e os pesos das camadas intermediárias vão sendo atualizados conforme o erro é retropropagado, o que caracteriza o treinamento com o back-propagation [9]. A Figura 3.8 ilustra estas duas fases.

\section{forward}

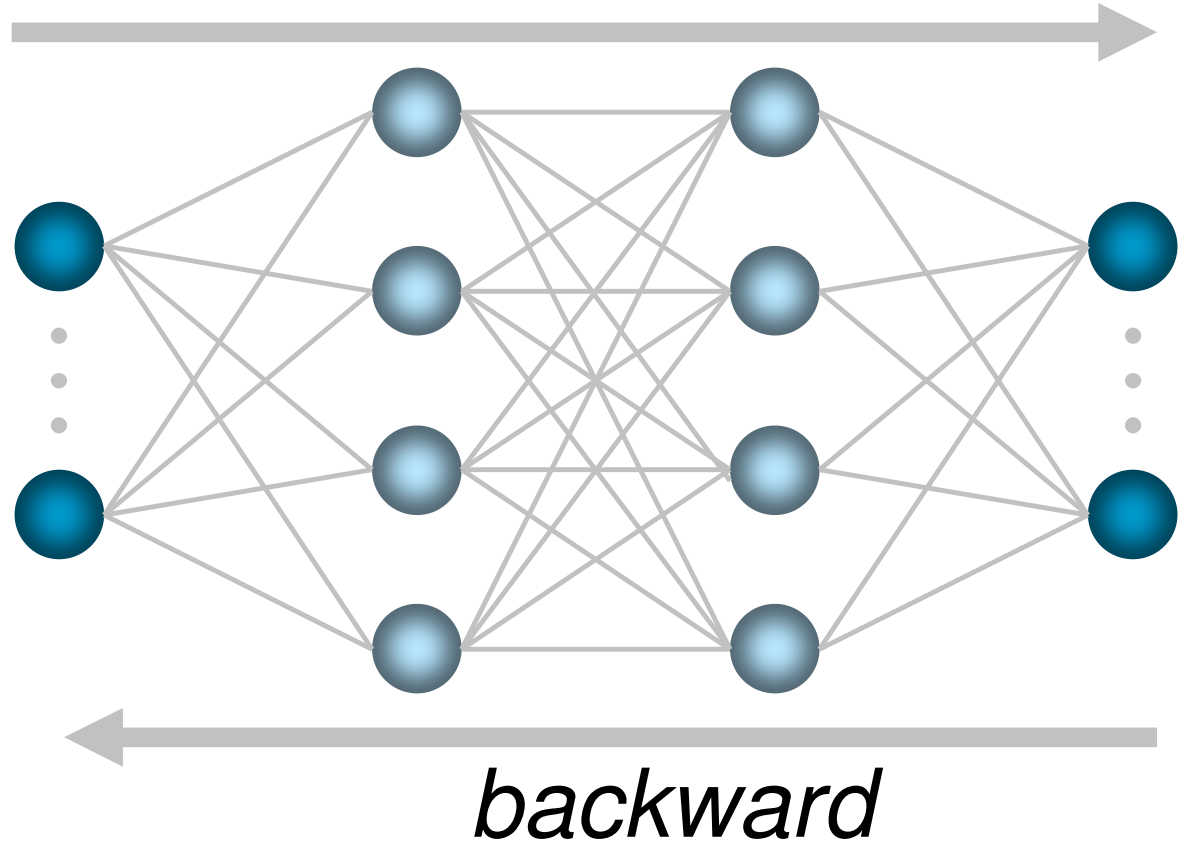

FIGURA 3.8 - Fluxo do processamento do algoritmo back-propagation. 
Para entender melhor o que acontece durante o treinamento, será apresentada a seqüência de passos que envolvem tanto a fase forward quanto a fase backward.

Passos que envolvem a fase forward:

1. A entrada é apresentada à primeira camada da rede e propagada em direção às saídas.

2. Os neurônios da camada intermediária $i$ calculam seus sinais de entrada que são propagados para a camada intermediária $i+1$

3. A última camada intermediária calcula seus sinais de saída e os envia à camada de saída.

4. As saídas produzidas pelos neurônios da última camada são então comparadas às saídas desejadas.

Se a saída produzida for próxima à saída desejada não haverá a fase backward e a resposta será apresentada; caso isso não aconteça, ativa-se a fase backward.

Passos que envolvem a fase backward:

1. A camada de saída calcula o erro da rede.

1.1 A camada de saída calcula o termo de correção dos pesos.

2. O erro é enviado da camada de saída para a camada intermediária $i+1$.

2.1 A camada intermediária $i+1$ calcula o seu erro.

2.2 Depois de calculado o erro da camada intermediária $i+1$, calcula-se o termo de correção dos pesos.

3. O erro é enviado da camada intermediária $i+1$ para a camada intermediária $i$. 


\subsection{A camada intermediária $i$ calcula o seu erro.}

3.2 Depois de calculado o erro da camada intermediária $i$, calcula-se o termo de correção dos pesos.

4. $\quad$ Cada unidade das camadas atualiza o seu peso.

Para compreender o processo de aprendizado do algoritmo, supõe-se que cada combinação de pesos e limiares corresponda a um ponto na superfície de solução. Considerando que a altura de um ponto é diretamente proporcional ao erro associado a este ponto, a solução está nos pontos mais baixos da superfície [10].

Para minimizar o erro obtido pela rede o algoritmo back-propagation ajusta os pesos e limiares, fazendo com que eles correspondam às coordenadas dos pontos mais baixos da superfície de erro [10].

Para que os pontos mais baixos da superfície de erro sejam atingidos é utilizado o método de gradiente descendente. Este método consegue encontrar a solução com erro mínimo para superfícies simples, mas não garante essa solução para superfícies mais complexas, pois o algoritmo pode ser levado a convergir para mínimos locais.

Assim, muitas vezes são encontradas dificuldades no treinamento do backpropagation, isso acontece devido a lentidão do algoritmo na solução de problemas complexos e sua tendência a convergir para mínimos locais da superfície de erro.

O back-propagation possui, basicamente, três parâmetros que determinam seu desempenho e sua capacidade de aprendizagem: taxa de aprendizagem, momentum e o número épocas. A taxa de aprendizagem é um parâmetro muito importante no processo de treinamento, pois interfere no tempo de aprendizado e na convergência da solução para um mínimo local ou global. O termo momentum é 
uma constante que determina o efeito das mudanças passadas dos pesos na direção atual do treinamento, que tem por objetivo permitir o aumento na velocidade de convergência. O número de épocas fornece a quantidade de vezes que o conjunto de treinamento será apresentado à rede a fim de que a mesma realize o ajuste de seus parâmetros livres.

\subsection{Aplicações de redes neurais artificiais no controle de qualidade de alimentos}

As indústrias de alimentos já vêm utilizando aplicações de redes neurais como classificadores de padrões no processo de controle de qualidade.

O uso de redes neurais para o controle de qualidade nas indústrias tem aumentado devido às suas capacidades de aprender, se adaptar, organizar e por sua rapidez. Podemos encontrar na literatura alguns trabalhos referentes ao uso de redes neurais no controle de qualidade.

O'Farrell et al. [19, 26] têm demonstrado aplicações de redes neurais como classificador dos dados obtidos pelo sensor de fibra óptica, desenvolvido para monitorar a cor do alimento quando estiverem no forno industrial em grande escala, usando espectroscopia de luz visível. Essas cores são agrupadas de acordo com o estágio de cozimento, podendo ser definidas por: cru, claro, assado, escuro e queimado. Esse sistema permite que o cliente escolha qual a cor do produto o satisfaz. As amostras utilizadas para esse trabalho foram hambúrgueres de frango com $8 \mathrm{~cm}$ de diâmetro. Toda a classificação desse sistema foi feita usando redes 
perceptron multicamadas utilizando o algoritmo de treinamento back-propagation com momentum.

Sheridan et al. [20] relataram a utilização da rede neural perceptron e mapas auto-organizáveis de Kohonen no processo de controle de qualidade de carne de frango utilizando sensor de fibra óptica para a coleta dos dados. O sensor monitora a cor do alimento por examinar a luz refletida da superfície da amostra.

Aplicações de redes neurais e lógicas fuzzy foram também utilizadas no controle de qualidade do bolo de arroz por Kypongsak et al. [21]. Os bolos de arroz foram produzidos com arroz marrom.

Gestal et al. [28] utilizaram redes neurais artificiais e algoritmos genéticos para classificar os dados de suco de maçã, analisados pela técnica de infravermelho. Diversas outras técnicas analíticas podem ser usadas para análises químicas, como: cromatografia gasosa, cromatografia líquida de alta resolução e métodos isotópicos, mas estas técnicas são caras e lentas.

Redes neurais artificiais são usadas como uma alternativa eficiente para realizar tarefas de classificação e reconhecimento de padrões, sendo aplicadas em diversos campos, como: automação da interpretação espectral de infravermelho, no estudo de adulteração de comida, usando espectroscopia de ressonância magnética por imagens, etc. 


\section{Processamento de Sinais de Ressonância} Magnética Nuclear para Classificação de Carne Bovina Usando Redes Neurais

\section{Artificiais}

As amostras de carne bovina foram provenientes do cruzamento entre animais de grupos genéticos distintos, onde os pais são de puro sangue e as mães com misturas de raças como apresentado na Figura 4.1. Para caracterizar as raças dos animais, adotaram-se os termos AX, BX e CX para os pais e TA e TS para as mães, representando os seguintes grupos genéticos:

- $\mathrm{AX} \rightarrow$ animais cruzados filhos de touros da raça Angus;

- $\mathrm{BX} \rightarrow$ animais cruzados filhos de touros da raça Bonsmara;

- $\mathrm{CX} \rightarrow$ animais cruzados filhos de touros da raça Canchim;

- $\quad$ TA $\rightarrow$ animais filhos de vacas cruzadas Angus x Nelore;

- TS $\rightarrow$ animais filhos de vacas cruzadas Simental $x$ Nelore.

onde foram obtidos os cruzamentos entre os pais e mães mencionados acima, resultando nos grupos genéticos AXTA, AXTS, BXTA, BXTS, CXTA e CXTS. 
Foram analisadas carnes de seis grupos genéticos em um total de 99 bovinos, sendo 21 animais AXTA, 14 animais AXTS, 20 animais BXTA, 16 animais BXTS, 15 animais CXTA e 13 animais CXTS. Destes, 56 eram machos e 43 fêmeas.

\section{Grupo genético do pai}

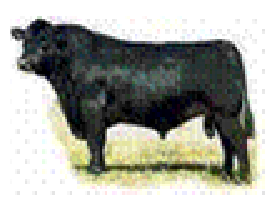

Raça Angus (AX)

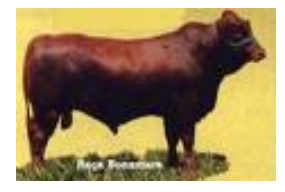

Raça Bonsmara (BX)

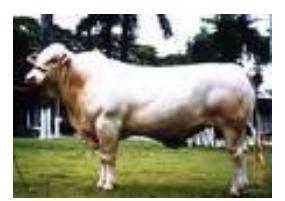

Raça Canchim (CX) Grupo genético da mãe

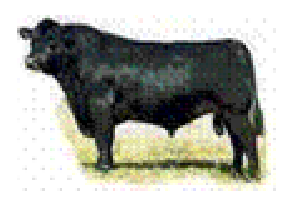

Raça Angus

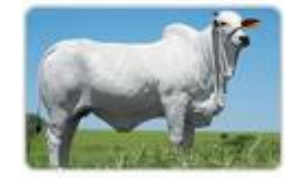

Raça Nelore

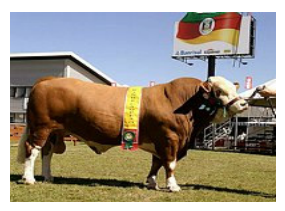

Raça Simental

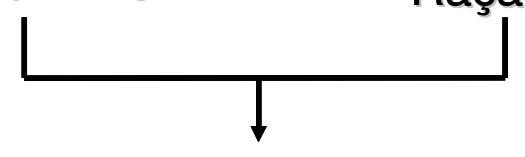

TA

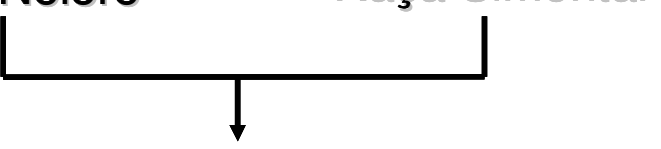

TS

FIGURA 4.1 - Grupo genético dos pais e das mães dos animais analisados.

Para analisar essas amostras de carne, utilizou-se a ferramenta de aplicação de rede neural e funções de treinamento do sistema WEKA, desenvolvido em JAVA [11].

A Figura 4.2 ilustra a janela do sistema, onde os dados são preparados para o processo de classificação. Na função Classify é montada a arquitetura da rede, 
com os valores da taxa de aprendizagem, momentum, número de épocas, entre outros.

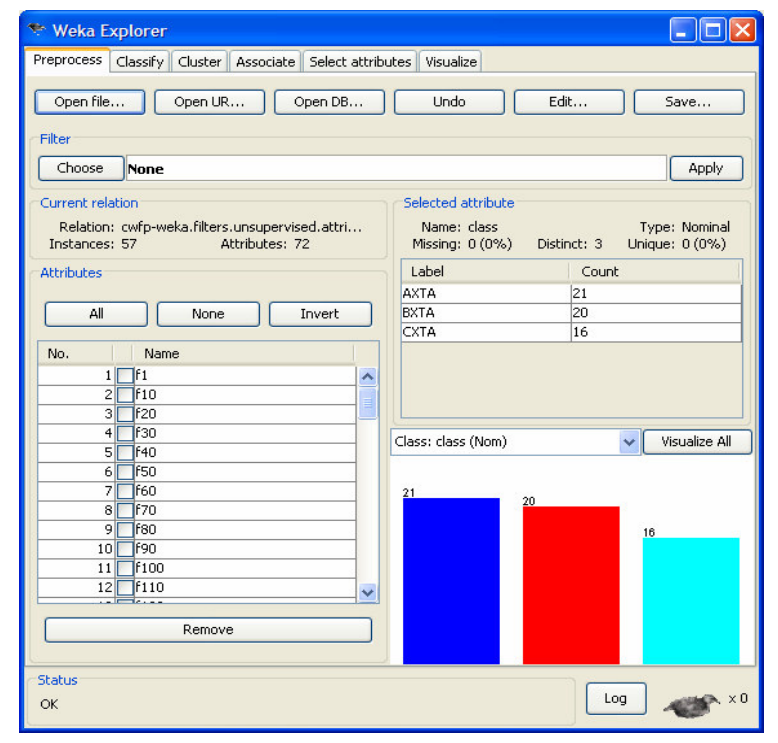

FIGURA 4.2 - Janela de preparação dos dados para a classificação por redes neurais do sistema WEKA.

\subsection{Obtenção dos sinais de ressonância magnética nuclear}

Os sinais de RMN de baixa resolução foram obtidos em um ímã supercondutor de 2,1Teslas e $30 \mathrm{~cm}$ de "bore" da Oxford em conjunto com um console CAT 100, da Tecmag, amplificador de potência 2035 AMT e um préamplificador AU1448 da Miteq.

As amostras de carne frescas foram colocadas nos probes (sondas), desenvolvidos na EMBRAPA Instrumentação Agropecuária. Esses probes são constituídos de um circuito eletrônico do tipo LC (indutor-capacitor), no qual são utilizados dois capacitores variáveis e uma bobina solenoidal indutora. 
A Figura 4.3 ilustra o equipamento de RMN, no qual o ímã foi utilizado para as análises de carne bovina e a Figura 4.4 ilustra o conjunto de equipamentos eletrônicos utilizados para enviar e receber os sinais do equipamento de RMN.

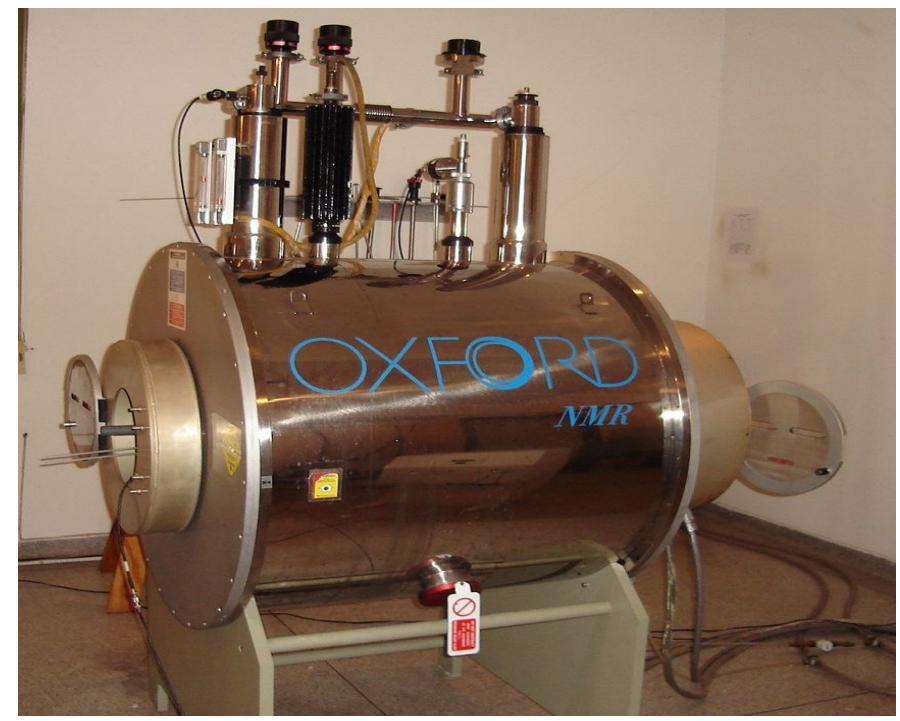

FIGURA 4.3 - Equipamento de ressonância magnética nuclear.

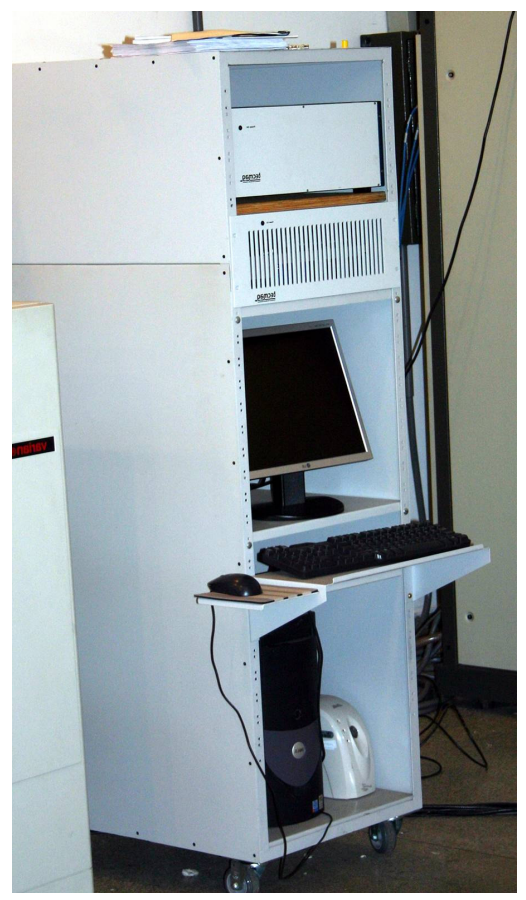

FIGURA 4.4 - Parte eletrônica ligada ao equipamento de RMN. 
A Figura 4.5 ilustra um diagrama em blocos de um espectrômetro de RMN.

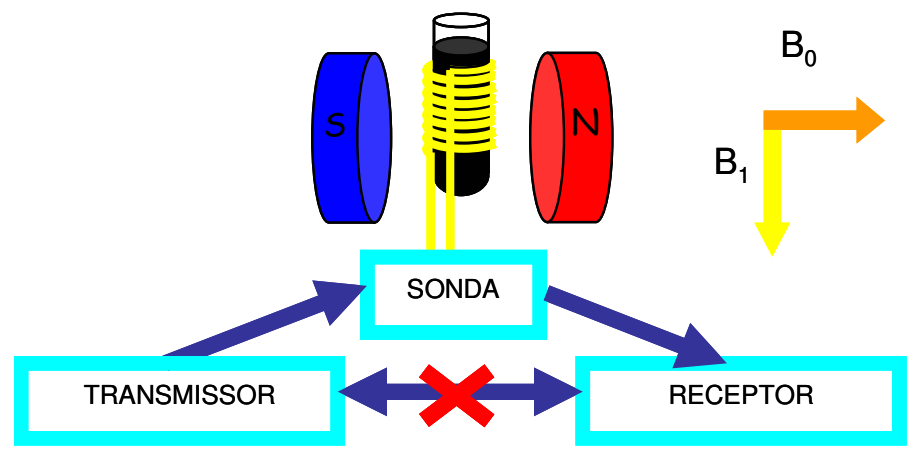

FIGURA 4.5 - Diagrama em blocos de um espectrômetro de RMN.

Num experimento de RMN a amostra é colocada numa sonda (representada pela bobina solenoidal) situada no interior de um campo magnético intenso $\left(B_{0}\right)$, que orienta os spins nucleares. Neste campo os spins precessionam com uma freqüência característica, denominada de freqüência de Larmor. Em seguida, a amostra é irradiada com um pulso de campo magnético oscilante $\left(B_{1}\right)$, perpendicular a $B_{0}$ gerado no transmissor. Esse pulso ou trem de pulsos de radiofreqüência (RF), na mesma freqüência de precessão, desloca a magnetização do estado de equilíbrio excitando então os spins $[4,24]$.

Após a excitação com RF, a amostra emite um sinal conhecido como FID (Free Induction Decay), que é amplificado e detectado no receptor. Esse sinal é seqüencialmente digitalizado e armazenado em um computador, onde suas intensidades, freqüências e tempo de decaimento podem ser usados em análises físico-químicas [17,29].

As amostras de carnes frescas analisadas foram extraídas do contra-filé, na região da sexta costela destes animais. Tais amostras foram colocadas no equipamento de RMN, sendo aplicadas técnicas de CPMG e CWFP, onde os dados 
extraídos foram utilizados como atributos de entrada para a rede neural artificial. A Figura 4.6 ilustra uma peça de contra-filé utilizada como amostra, analisada pelo equipamento de RMN.

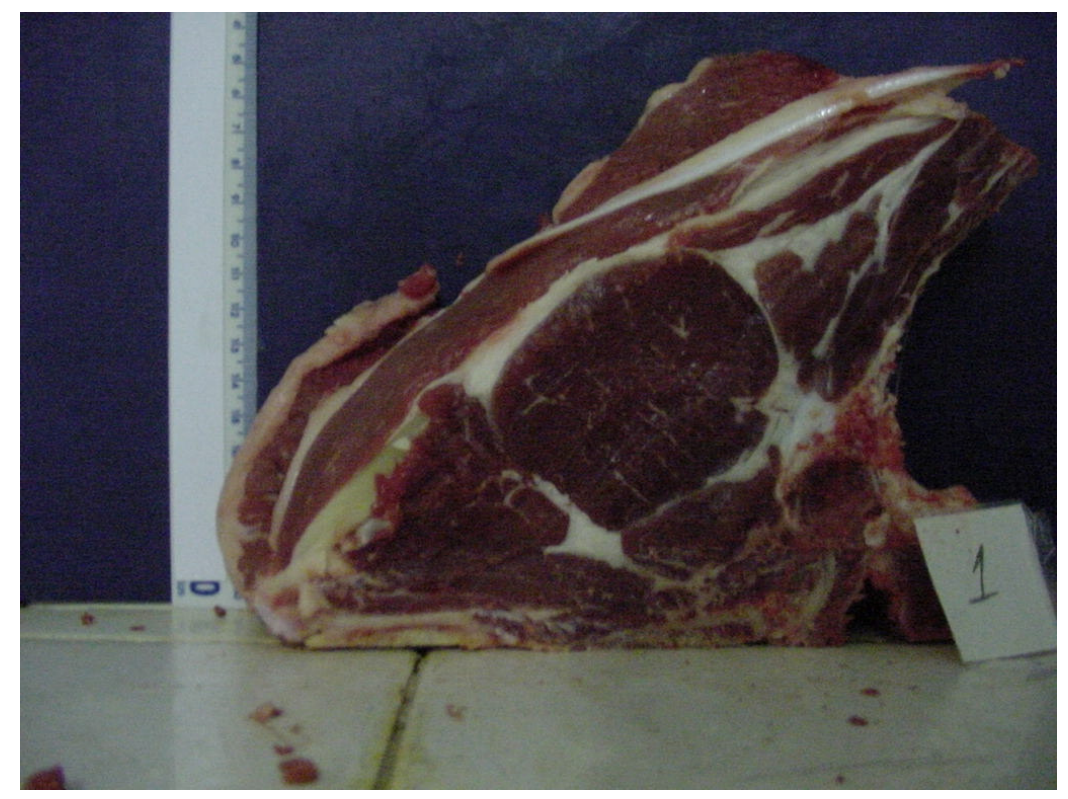

FIGURA 4.6 - Foto de um bife de contra-filé utilizado nas análises.

Os sinais de CPMG e CWFP geram curvas de decaimentos com 500 e 700 pontos, respectivamente, para cada amostra de carne. Cada ponto dessas curvas traz características referentes à amostra de carne analisada, estando relacionadas com a quantidade de gordura, quantidade de água na carne, $\mathrm{pH}$, entre outros, por isso consegue-se diferenciar um animal do outro. Na Figura 4.7 são apresentadas cinco curvas de decaimento (CWFP) de amostras de carnes provenientes da sexta costela de bovinos.

Fazendo uma comparação entre as duas técnicas, utilizam-se as mesmas amostras de carne da Figura 4.7 para a composição da curva de decaimento da Figura 4.8, sendo que esta usou a técnica de CPMG. 
Pode-se observar que mesmo sendo de amostras iguais, as curvas de decaimento apresentam características diferentes.

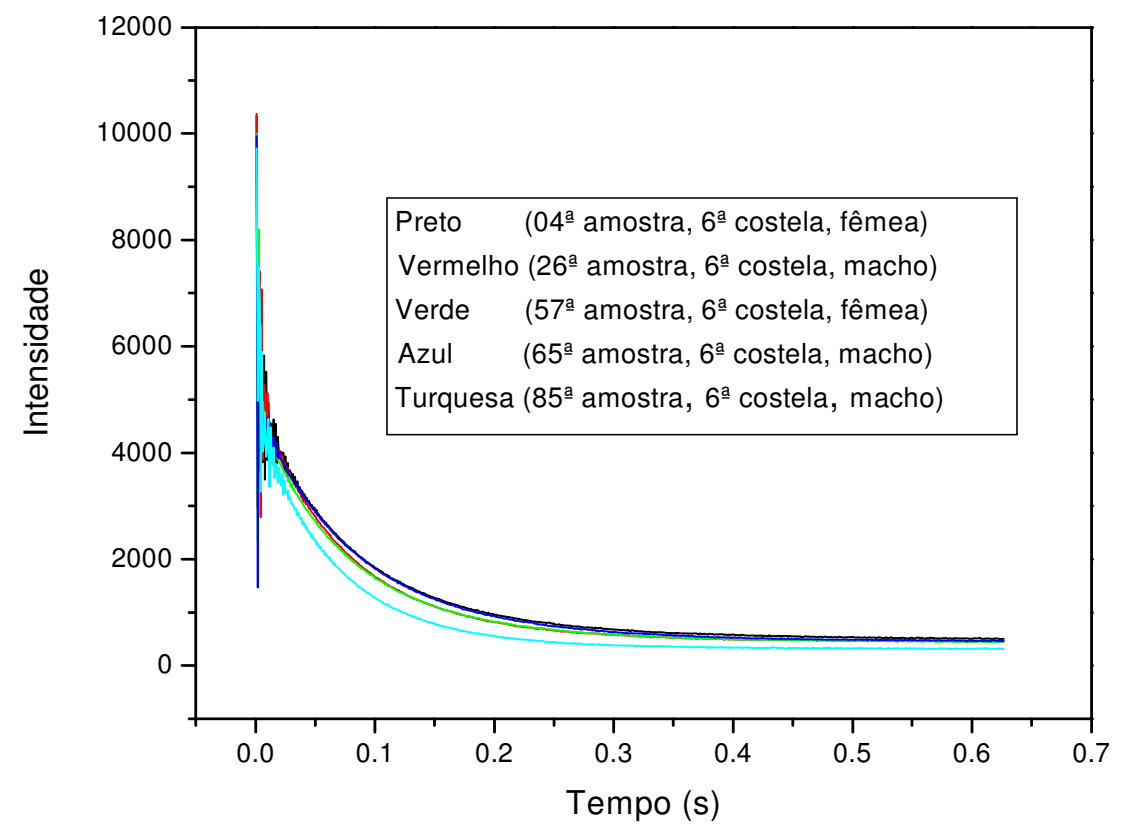

FIGURA 4.7 - Curva de decaimento de CWFP das amostras de carnes bovinas relacionadas ao sexo dos animais.

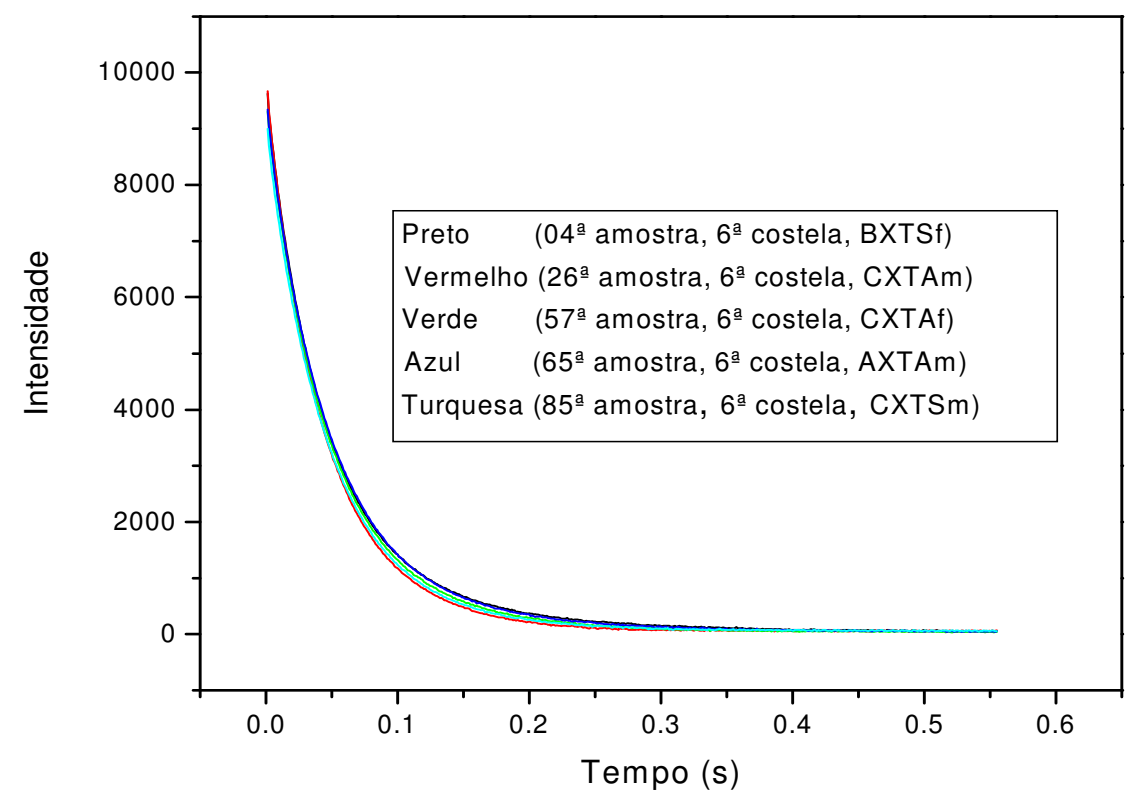

FIGURA 4.8 - Curva de decaimento de CPMG das amostras de carnes bovinas relacionadas ao grupo genético. 
Observa-se também uma variação mínima entre as curvas de decaimento, tornando difícil a visualização e diferenciação entre os grupos genéticos (CPMG) apresentados pela Figura 4.8 e os sexos dos animais (Figura 4.7).

\subsection{Arquitetura neural para classificação de carne bovina referente ao grupo genético}

As amostras de carne, depois de colocadas no equipamento de RMN são analisadas pelas técnicas de CPMG e CWFP. Tais técnicas apresentam uma seqüência de pulsos, que serão repetidas para a obtenção de uma média. As técnicas de CPMG e CWFP têm por característica um decaimento exponencial em relação ao tempo, como podem ser observadas pelas Figuras 4.7 e 4.8. Os pontos de tais curvas de decaimento serão utilizados como atributos de entrada para o treinamento e classificação da rede perceptron.

As principais características que distinguem uma amostra da outra são fornecidas no começo da curva, quando a intensidade do sinal é alta. Tais características tendem a reduzir conforme o tempo vai aumentando, pois a intensidade do sinal é inversamente proporcional ao tempo.

$\mathrm{Na}$ etapa de pré-processamento da classificação dos grupos genéticos referentes às amostras de carne analisadas pela técnica de CPMG, os atributos de entrada foram selecionados de forma não igualmente espaçada. Tal critério de seleção proporcionou melhores resultados na saída do classificador, do que quando usados todos os atributos disponíveis. 
No primeiro estudo realizado para a classificação do grupo genético, utilizouse para o treinamento da rede todas as amostras dos animais machos ( $A X, B X$ e CX) e apenas de uma fêmea por vez.

A Tabela 4.1 apresenta os parâmetros utilizados para a classificação dos grupos genéticos, utilizando os dados dos cruzamentos de AXTA, BXTA e CXTA. Neste treinamento, conforme citado anteriormente, os atributos de entrada foram obtidos de forma a não ficarem igualmente espaçados no tempo, pois, estes foram tomados de forma mais densa em curto espaço de tempo e assim a densidade de dados foi diminuindo de acordo com o aumento do tempo, porém, de modo constante. Os pontos provenientes da técnica de CPMG utilizados neste caso foram, $1,3,5,7,9,11,13,19,24,30,40,50,60,70,80,90,100,115,130,145$, $160,175,190,205,220,235,250,265,280,295,310,330,350,370,390,410,430$, $450,470,490$, totalizando assim quarenta atributos de entrada.

TABELA 4.1 - Parâmetros de treinamento da MLP (CPMG) - Classificação do grupo genético (TA) com dados não igualmente espaçados.

\begin{tabular}{|c|c|}
\hline Parâmetros & Valores \\
\hline Taxa de aprendizagem (Learning Rate) & 0.25 \\
\hline Momentum & 0.15 \\
\hline Número de épocas & 900 \\
\hline Número de camadas intermediárias & 1 \\
\hline Sinais da camada de entrada & 40 \\
\hline Neurônios da camada intermediária & 21 \\
\hline Neurônio da camada de saída & 3 \\
\hline Cross-validation (folds) & 10 \\
\hline
\end{tabular}

A Tabela 4.2 apresenta os dados utilizados para a classificação dos grupos genéticos, utilizando os dados dos cruzamentos de AXTS, BXTS e CXTS. Neste 
treinamento, os atributos de entrada foram selecionados da mesma maneira do treinamento anterior.

TABELA 4.2 - Parâmetros de treinamento da MLP (CPMG) - Classificação do grupo genético (TS) com dados não igualmente espaçados.

\begin{tabular}{|c|c|}
\hline Parâmetros & Valores \\
\hline Taxa de aprendizagem (Learning Rate) & 0.2 \\
\hline Momentum & 0.2 \\
\hline Número de épocas & 900 \\
\hline Número de camadas intermediárias & 1 \\
\hline Sinais da camada de entrada & 40 \\
\hline Neurônios da camada intermediária & 21 \\
\hline Neurônio da camada de saída & 3 \\
\hline Cross-validation (folds) & 10 \\
\hline
\end{tabular}

Outros métodos de classificação dos grupos genéticos foram estudados. Um desses métodos investigados foi a criação de um classificador que utilizasse todas as amostras dos animais fêmeas (TA e TS) e de apenas um macho de cada vez, ao contrário do método apresentado anteriormente, onde foram utilizadas todas as amostras dos animais machos e apenas de uma fêmea por vez. Os resultados dos dois métodos serão comparados posteriormente.

A Tabela 4.3 apresenta os dados utilizados para a classificação dos grupos genéticos, utilizando os dados dos cruzamentos de AXTA e AXTS. Neste treinamento, os atributos de entrada foram obtidos de forma a não ficarem igualmente espaçados no tempo, pois, estes foram tomados de forma mais densa em curto espaço de tempo e assim a densidade de dados foi diminuindo de acordo com o aumento do tempo, porém, de modo constante. Os pontos provenientes da técnica de CPMG utilizados neste caso foram os mesmos utilizados para o método anterior. 
TABELA 4.3 - Parâmetros de treinamento da MLP (CPMG) - Classificação do grupo genético $(A X)$ com dados não igualmente espaçados.

\begin{tabular}{|c|c|}
\hline Parâmetros & Valores \\
\hline Taxa de aprendizagem (Learning Rate) & 0.05 \\
\hline Momentum & 0.05 \\
\hline Número de épocas & 500 \\
\hline Número de camadas intermediárias & 1 \\
\hline Sinais da camada de entrada & 40 \\
\hline Neurônios da camada intermediária & 21 \\
\hline Neurônio da camada de saída & 2 \\
\hline Cross-validation (folds) & 10 \\
\hline
\end{tabular}

A Tabela 4.4 apresenta os dados utilizados para a classificação dos grupos genéticos, utilizando os dados dos cruzamentos de BXTA e BXTS. Neste treinamento, os atributos de entrada foram selecionados da mesma maneira do treinamento anterior, porém com os seguintes pontos: 1, 10, 20, 30, 40, 50, 60, 70, $80,90,100,115,130,145,160,175,190,205,220,235,250,265,280,295,310$, $330,350,370,390,410,430,450,490$, totalizando assim trinta e quatro atributos de entrada na rede MLP.

TABELA 4.4 - Parâmetros de treinamento da MLP (CPMG) - Classificação do grupo genético $(B X)$ com dados não igualmente espaçados.

\begin{tabular}{|c|c|}
\hline Parâmetros & Valores \\
\hline Taxa de aprendizagem (Learning Rate) & 0.05 \\
\hline Momentum & 0.15 \\
\hline Número de épocas & 900 \\
\hline Número de camadas intermediárias & 1 \\
\hline Sinais da camada de entrada & 34 \\
\hline Neurônios da camada intermediária & 18 \\
\hline Neurônio da camada de saída & 2 \\
\hline Cross-validation (folds) & 10 \\
\hline
\end{tabular}


A Tabela 4.5 apresenta os dados utilizados para a classificação dos grupos genéticos, utilizando os dados dos cruzamentos de CXTA e CXTS. Neste treinamento, os atributos de entrada foram selecionados com os mesmos pontos utilizados nos outros métodos que tiveram como sinais da camada de entrada quarenta atributos.

TABELA 4.5 - Parâmetros de treinamento da MLP (CPMG) - Classificação do grupo genético $(C X)$ com dados não igualmente espaçados.

\begin{tabular}{|c|c|}
\hline Parâmetros & Valores \\
\hline Taxa de aprendizagem (Learning Rate) & 0.3 \\
\hline Momentum & 0.05 \\
\hline Número de épocas & 500 \\
\hline Número de camadas intermediárias & 1 \\
\hline Sinais da camada de entrada & 40 \\
\hline Neurônios da camada intermediária & 21 \\
\hline Neurônio da camada de saída & 2 \\
\hline Cross-validation (folds) & 10 \\
\hline
\end{tabular}

Utilizou-se para as amostras de carne analisadas pelo método de CWFP a mesma regra de seleção dos atributos de entrada para o treinamento da rede perceptron usadas no método de CPMG.

Como na técnica anterior, realizou-se primeiramente o treinamento da rede para a classificação dos grupos genéticos utilizando todas as amostras dos animais machos $(A X, B X$ e $C X)$ e apenas de uma fêmea por vez. A Tabela 4.6 apresenta os dados utilizados no treinamento do grupo genético dos bovinos, usando os dados advindos dos cruzamentos AXTA, BXTA e CXTA. Neste treinamento, os atributos de entrada foram obtidos de forma a ficarem igualmente espaçados no tempo. Os pontos selecionados neste caso foram selecionados de 1 a 700 de 10 em 10, totalizando assim setenta e um atributos de entrada. 
TABELA 4.6 - Parâmetros de treinamento da MLP (CWFP) - Classificação do grupo genético (TA) com dados igualmente espaçado.

\begin{tabular}{|c|c|}
\hline Parâmetros & Valores \\
\hline Taxa de aprendizagem (Learning Rate) & 0.1 \\
\hline Momentum & 0.1 \\
\hline Número de épocas & 1500 \\
\hline Número de camadas intermediárias & 1 \\
\hline Sinais da camada de entrada & 71 \\
\hline Neurônios da camada intermediária & 37 \\
\hline Neurônio da camada de saída & 3 \\
\hline Cross-validation (folds) & 10 \\
\hline
\end{tabular}

O parâmetro apresentado na Tabela 4.7 está representado o treinamento da rede utilizada para classificar o grupo genético entre os cruzamentos AXTS, BXTS e CXTS. Neste caso, todos os atributos foram igualmente espaçados, da mesma maneira que o treinamento anterior, de $10 \mathrm{em} 10$.

TABELA 4.7 - Parâmetros de treinamento da MLP (CWFP) - Classificação do grupo genético (TS) com os dados igualmente espaçados.

\begin{tabular}{|c|c|}
\hline Parâmetros & Valores \\
\hline Taxa de aprendizagem (Learning Rate) & 0.2 \\
\hline Momentum & 0.1 \\
\hline Número de épocas & 1500 \\
\hline Número de camadas intermediárias & 1 \\
\hline Sinais da camada de entrada & 71 \\
\hline Neurônios da camada intermediária & 37 \\
\hline Neurônio da camada de saída & 3 \\
\hline Cross-validation (folds) & 10 \\
\hline
\end{tabular}

Depois do treinamento da rede perceptron, utilizando as fêmeas como padrões fixos, treinou-se a rede utilizando todas as amostras dos animais fêmeas (TA e TS) e apenas um macho por vez. Deste modo, foram construídos três classificadores de padrões. A Tabela 4.8 apresenta os dados utilizados para a 
classificação dos grupos genéticos, utilizando os dados dos cruzamentos de AXTA e AXTS. Neste treinamento, os pontos selecionados da curva de decaimento de CWFP foram os seguintes: $1,3,5,7,9,11,13,17,21,25,29,35,40,45,50,55,60,70$, $80,90,100,110,120,130,140,150,160,170,180,210,240,270,300,330,370$, $410,450,490,530,580,630,680$, totalizando assim quarenta e dois atributos.

Conforme observado, os atributos de entrada neste treinamento foram obtidos de forma a não ficarem igualmente espaçados no tempo, pois, estes foram tomados de forma mais densa em curto espaço de tempo e assim a densidade de dados foi diminuindo de acordo com o aumento do tempo, porém, de modo constante.

TABELA 4.8 - Parâmetros de treinamento da MLP (CWFP) - Classificação do grupo genético $(A X)$ com dados não igualmente espaçados.

\begin{tabular}{|c|c|}
\hline Parâmetros & Valores \\
\hline Taxa de aprendizagem (Learning Rate) & 0.05 \\
\hline Momentum & 0.05 \\
\hline Número de épocas & 500 \\
\hline Número de camadas intermediárias & 1 \\
\hline Sinais da camada de entrada & 42 \\
\hline Neurônios da camada intermediária & 22 \\
\hline Neurônio da camada de saída & 2 \\
\hline Cross-validation (folds) & 10 \\
\hline
\end{tabular}

O parâmetro apresentado na Tabela 4.9 está representando o treinamento da rede utilizada para classificar o grupo genético entre os cruzamentos de BXTA e BXTS. Neste treinamento, os atributos de entrada foram selecionados da mesma maneira do treinamento anterior. 
TABELA 4.9 - Parâmetros de treinamento da MLP (CWFP) - Classificação do grupo genético (BX) com dados não igualmente espaçados.

\begin{tabular}{|c|c|}
\hline Parâmetros & Valores \\
\hline Taxa de aprendizagem (Learning Rate) & 0.1 \\
\hline Momentum & 0.05 \\
\hline Número de épocas & 1500 \\
\hline Número de camadas intermediárias & 1 \\
\hline Sinais da camada de entrada & 42 \\
\hline Neurônios da camada intermediária & 22 \\
\hline Neurônio da camada de saída & 2 \\
\hline Cross-validation (folds) & 10 \\
\hline
\end{tabular}

A Tabela 4.10 apresenta os dados utilizados para a classificação dos grupos genéticos utilizando os dados dos cruzamentos de CXTA e CXTS. Neste treinamento, os atributos de entrada foram selecionados de forma quase similar a do treinamento anterior, totalizando quarenta e um atributos de entrada. Os pontos selecionados da curva de decaimento de CWFP foram os seguintes: 1, 3, 5, 7, 9, 11, $13,17,21,25,29,35,40,45,50,60,70,80,90,100,110,120,130,140,150,160$, $170,180,210,240,270,300,330,370,410,450,490,530,580,630,680$.

TABELA 4.10 - Parâmetros de treinamento da MLP (CWFP) - Classificação do grupo genético $(C X)$ com dados não igualmente espaçado.

\begin{tabular}{|c|c|}
\hline Parâmetros & Valores \\
\hline Taxa de aprendizagem (Learning Rate) & 0.25 \\
\hline Momentum & 0.05 \\
\hline Número de épocas & 500 \\
\hline Número de camadas intermediárias & 1 \\
\hline Sinais da camada de entrada & 41 \\
\hline Neurônios da camada intermediária & 21 \\
\hline Neurônio da camada de saída & 2 \\
\hline Cross-validation (folds) & 10 \\
\hline
\end{tabular}




\subsection{Arquitetura neural para a classificação de carne bovina referente ao sexo do animal}

Como mencionado no começo deste trabalho, o sexo do animal é um dos parâmetros que interfere na composição nutricional da carne. Por isso, construiu-se um classificador de padrões com a finalidade de separar os machos das fêmeas, utilizando todas as 99 amostras disponibilizadas para este estudo e tendo como base os mesmos princípios utilizados na classificação dos grupos genéticos.

$\mathrm{Na}$ etapa de pré-processamento da classificação do sexo do animal, referente às amostras de carne analisadas pela técnica de CPMG, os atributos de entrada foram selecionados de forma não igualmente espaçada. Tal critério de seleção proporcionou melhores resultados na saída do classificador do que quando usados todos os 500 atributos disponíveis.

Utilizou-se uma rede perceptron multicamadas como classificador de padrões das amostras de carne bovina, referente à técnica CPMG. Os parâmetros utilizados para a modelagem da rede são dispostos na Tabela 4.11. Neste caso, os pontos selecionados da curva de decaimento de CPMG foram os seguintes: 1, 3, 5, $7,9,11,13,17,21,25,29,35,40,45,50,60,70,80,90,100,110,120,130,140$, $150,160,170,180,210,240,270,290,330,370,410,450$ e 490, totalizando assim trinta e sete atributos. 
TABELA 4.11 - Parâmetros de treinamento da MLP (CPMG) - Classificação do sexo.

\begin{tabular}{|c|c|}
\hline Parâmetros & Valores \\
\hline Taxa de aprendizagem (Learning Rate) & 0.25 \\
\hline Momentum & 0.05 \\
\hline Número de épocas & 900 \\
\hline Número de camadas intermediárias & 1 \\
\hline Sinais da camada de entrada & 37 \\
\hline Neurônios da camada intermediária & 19 \\
\hline Neurônio da camada de saída & 2 \\
\hline Cross-validation (folds) & 10 \\
\hline
\end{tabular}

Utilizou-se para as amostras analisadas pelo método de CWFP a mesma regra de seleção dos atributos de entrada para o treinamento da rede usada pelo método de CPMG. A Tabela 4.12 apresenta os parâmetros utilizados no treinamento da rede para a classificação do sexo, referentes aos dados da técnica de CWFP. Neste caso, os pontos selecionados da curva de decaimento de CWFP foram os seguintes: $1,3,5,7,9,11,13,17,21,25,29,35,40,45,50,55,60,70,80$, $90,100,110,120,130,140,150,160,170,180,210,240,270,300,330,370,410$, $450,490,530,580,630,680$, totalizando assim quarenta e três atributos.

TABELA 4.12 - Parâmetros de treinamento da MLP (CWFP) - Classificação do sexo.

\begin{tabular}{|c|c|}
\hline Parâmetros & Valores \\
\hline Taxa de aprendizagem (Learning Rate) & 0.25 \\
\hline Momentum & 0.05 \\
\hline Número de épocas & 900 \\
\hline Número de camadas intermediárias & 1 \\
\hline Sinais da camada de entrada & 43 \\
\hline Neurônios da camada intermediária & 22 \\
\hline Neurônio da camada de saída & 2 \\
\hline Cross-validation (folds) & 10 \\
\hline
\end{tabular}


No treinamento da rede perceptron multicamadas para as classificações dos padrões do grupo genético e do sexo foi utilizado o método 10-fold stratified crossvalidation. Neste método os dados utilizados para o treinamento foram divididos aleatoriamente em 10 grupos mutuamente exclusivos (folds) com tamanho e distribuição de classes aproximadamente iguais. Um fold é separado para teste (um conjunto de novos exemplos a serem apresentados) e os 9 folds restantes são utilizados para treinamento da rede. Cada par (fold de teste, fold de treinamento) constitui uma iteração para a validação do algoritmo, totalizando 10 iterações. Após o processo de aprendizagem utilizando o fold de treinamento, o fold de teste é apresentado à rede em questão e o erro de classificação é calculado. Esse processo é repetido para os 9 folds restantes.

Em seguida, a média $(m d)$ e o desvio padrão $(s d)$ dos erros obtidos nas 10 iterações são calculados por:

$$
\begin{gathered}
m d(A)=\frac{1}{r} \sum_{i=1}^{r} \operatorname{err}\left(h_{i}\right) \\
s d(A)=\sqrt{\frac{1}{r}}\left[\frac{1}{r-1} \sum_{i=1}^{r}\left(\operatorname{err}\left(h_{i}\right)-m d(A)\right)^{2}\right]
\end{gathered}
$$

onde:

- $\quad m d(A) \rightarrow$ Média dos erros de validação no fold de teste das $r$ hipóteses (classificadores) $h_{i}$ geradas.

- $A \rightarrow$ Algoritmo de aprendizado considerado.

- $\operatorname{err}\left(h_{i}\right) \rightarrow$ Taxa de erro da MLP $h_{i}$

- $\quad s d(A) \rightarrow$ Desvio padrão do algoritmo $A$. 
A estimativa de desempenho em validação cruzada fornece argumentos $(m d(A) \pm s d(A))$ conclusivos sobre o desempenho futuro da rede considerando um algoritmo $A[18]$.

\subsection{Resultados das aplicações das arquiteturas neurais desenvolvidas}

Primeiramente, realizaram-se diversas investigações com o objetivo de se projetar uma arquitetura de rede neural artificial que fosse capaz de classificar e separar os grupos genéticos. Essas investigações foram realizadas modificando os números de atributos apresentados à rede de forma que essa tivesse um melhor desempenho.

Os melhores desempenhos apresentados pela rede em relação à classificação dos grupos genéticos, baseado nos dados de CPMG, estão especificados nas Tabelas 4.1 e 4.2, tendo seus resultados apresentados pelas Tabelas 4.13 e 4.14, respectivamente.

TABELA 4.13 - Acurácia da MLP (CPMG) para estimativa do grupo genético dos animais (TA).

\begin{tabular}{|c|c|c|c|}
\hline Raça & $\begin{array}{c}\text { Total de } \\
\text { amostras }\end{array}$ & $\begin{array}{c}\text { Total de } \\
\text { acertos }\end{array}$ & Acurácia (\%) \\
\hline AXTA & 21 & 8 & 38,10 \\
\hline BXTA & 20 & 10 & 50,00 \\
\hline CXTA & 15 & 7 & 46,67 \\
\hline Total & 56 & 25 & 43,86 \\
\hline
\end{tabular}


TABELA 4.14 - Acurácia da MLP (CPMG) para estimativa do grupo genético dos animais (TS).

\begin{tabular}{|c|c|c|c|}
\hline Raça & $\begin{array}{c}\text { Total de } \\
\text { amostras }\end{array}$ & $\begin{array}{c}\text { Total de } \\
\text { acertos }\end{array}$ & Acurácia (\%) \\
\hline AXTS & 14 & 7 & 50,00 \\
\hline BXTS & 16 & 8 & 50,00 \\
\hline CXTS & 13 & 5 & 38,46 \\
\hline Total & 43 & 20 & 46,51 \\
\hline
\end{tabular}

As Tabelas $4.15,4.16$ e 4.17 apresentam os melhores resultados alcançados pela rede treinada com os parâmetros apresentados pelas Tabelas 4.3, 4.4 e 4,5, respectivamente.

TABELA 4.15 - Acurácia da MLP (CPMG) para estimativa do grupo genético dos animais $(A X)$.

\begin{tabular}{|c|c|c|c|}
\hline Raça & $\begin{array}{c}\text { Total de } \\
\text { amostras }\end{array}$ & $\begin{array}{c}\text { Total de } \\
\text { acertos }\end{array}$ & Acurácia (\%) \\
\hline AXTA & 21 & 18 & 85,71 \\
\hline AXTS & 14 & 9 & 64,29 \\
\hline Total & 35 & 27 & 77,14 \\
\hline
\end{tabular}

TABELA 4.16 - Acurácia da MLP (CPMG) para estimativa do grupo genético dos animais $(B X)$.

\begin{tabular}{|c|c|c|c|}
\hline Raça & $\begin{array}{c}\text { Total de } \\
\text { amostras }\end{array}$ & $\begin{array}{c}\text { Total de } \\
\text { acertos }\end{array}$ & Acurácia (\%) \\
\hline BXTA & 20 & 11 & 55,00 \\
\hline BXTS & 16 & 5 & 31,25 \\
\hline Total & 36 & 16 & 44,44 \\
\hline
\end{tabular}


TABELA 4.17 - Acurácia da MLP (CPMG) para estimativa do grupo genético dos animais $(C X)$.

\begin{tabular}{|c|c|c|c|}
\hline Raça & $\begin{array}{c}\text { Total de } \\
\text { amostras }\end{array}$ & $\begin{array}{c}\text { Total de } \\
\text { acertos }\end{array}$ & Acurácia (\%) \\
\hline CXTA & 15 & 11 & 73,33 \\
\hline CXTS & 13 & 7 & 53,85 \\
\hline Total & 28 & 18 & 64,29 \\
\hline
\end{tabular}

Foram realizadas diversas investigações, modificando os números de atributos apresentados à rede, com o objetivo de se projetar uma arquitetura de rede neural artificial que fosse tambémcapaz de classificar e separar os grupos genéticos baseados nos dados de CWFP com o menor número de erros possíveis.

Os melhores desempenhos apresentados pela rede em relação à classificação dos grupos genéticos, baseado nos dados de CWFP, especificados nas Tabelas 4.6 e 4.7, tendo seus resultados apresentados pelas Tabelas 4.18 e 4.19 , respectivamente.

TABELA 4.18 - Acurácia da MLP (CWFP) para estimativa do grupo genético dos animais (TA).

\begin{tabular}{|c|c|c|c|}
\hline Raça & $\begin{array}{c}\text { Total de } \\
\text { amostras }\end{array}$ & $\begin{array}{c}\text { Total de } \\
\text { acertos }\end{array}$ & Acurácia (\%) \\
\hline AXTA & 21 & 11 & 52,38 \\
\hline BXTA & 20 & 10 & 50,00 \\
\hline CXTA & 15 & 3 & 20,00 \\
\hline Total & 56 & 24 & 42,86 \\
\hline
\end{tabular}


TABELA 4.19 - Acurácia da MLP (CWFP) para estimativa do grupo genético dos animais (TS).

\begin{tabular}{|c|c|c|c|}
\hline Raça & $\begin{array}{c}\text { Total de } \\
\text { amostras }\end{array}$ & $\begin{array}{c}\text { Total de } \\
\text { acertos }\end{array}$ & Acurácia (\%) \\
\hline AXTS & 14 & 6 & 42,86 \\
\hline BXTS & 16 & 8 & 50,00 \\
\hline CXTS & 13 & 6 & 46,15 \\
\hline Total & 43 & 20 & 46,51 \\
\hline
\end{tabular}

As Tabelas $4.20,4.21$ e 4.22 apresentam os melhores resultados alcançados pela rede treinada com os parâmetros apresentados pelas Tabelas 4.8, 4.9 e 4,10 , respectivamente.

TABELA 4.20 - Acurácia da MLP (CWFP) para estimativa do grupo genético dos animais $(A X)$.

\begin{tabular}{|c|c|c|c|}
\hline Raça & $\begin{array}{c}\text { Total de } \\
\text { amostras }\end{array}$ & $\begin{array}{c}\text { Total de } \\
\text { acertos }\end{array}$ & Acurácia (\%) \\
\hline AXTA & 21 & 17 & 80,95 \\
\hline AXTS & 14 & 6 & 42,86 \\
\hline Total & 35 & 23 & 65,71 \\
\hline
\end{tabular}

TABELA 4.21 - Acurácia da MLP (CWFP) para estimativa do grupo genético dos animais $(B X)$.

\begin{tabular}{|c|c|c|c|}
\hline Raça & $\begin{array}{c}\text { Total de } \\
\text { amostras }\end{array}$ & $\begin{array}{c}\text { Total de } \\
\text { acertos }\end{array}$ & Acurácia (\%) \\
\hline BXTA & 20 & 10 & 50,00 \\
\hline BXTS & 16 & 9 & 56,25 \\
\hline Total & 36 & 19 & 52,78 \\
\hline
\end{tabular}


TABELA 4.22 - Acurácia da MLP (CWFP) para estimativa do grupo genético dos animais $(X)$.

\begin{tabular}{|c|c|c|c|}
\hline Raça & $\begin{array}{c}\text { Total de } \\
\text { amostras }\end{array}$ & $\begin{array}{c}\text { Total de } \\
\text { acertos }\end{array}$ & Acurácia (\%) \\
\hline CXTA & 15 & 13 & 86,67 \\
\hline CXTS & 13 & 8 & 61,54 \\
\hline Total & 28 & 21 & 75,00 \\
\hline
\end{tabular}

Após a classificação dos grupos genéticos foram projetadas duas redes neurais para classificação do sexo dos animais, utilizando também os dados de CPMG e CWFP. Os ajustes apresentados na Tabela 4.11 foram os melhores assumidos pela RNA para a determinação do sexo de bovinos provenientes dos dados de CPMG. Na Tabela 4.23 são apresentadas estimativas de acurácia por sexo do animal, bem como a estimativa total da MLP.

TABELA 4.23 - Acurácia da MLP (CPMG) para estimativa do sexo dos animais.

\begin{tabular}{|c|c|c|c|}
\hline Sexo & $\begin{array}{c}\text { Total de } \\
\text { amostras }\end{array}$ & $\begin{array}{c}\text { Total de } \\
\text { acertos }\end{array}$ & Acurácia (\%) \\
\hline Fêmea & 43 & 35 & 81,40 \\
\hline Macho & 56 & 48 & 85,71 \\
\hline Total & 99 & 83 & 83,84 \\
\hline
\end{tabular}

Já os ajustes apresentados na Tabela 4.12 foram os melhores assumidos pela RNA para a determinação do sexo de bovinos provenientes dos dados de CWFP. Na Tabela 4.24 são apresentadas estimativas de acurácia por sexo do animal, bem como a estimativa total da MLP. 
TABELA 4.24 - Acurácia da MLP (CWFP) para estimativa do sexo dos animais.

\begin{tabular}{|c|c|c|c|}
\hline Sexo & $\begin{array}{c}\text { Total de } \\
\text { amostras }\end{array}$ & $\begin{array}{c}\text { Total de } \\
\text { acertos }\end{array}$ & Acurácia (\%) \\
\hline Fêmea & 43 & 35 & 81,40 \\
\hline Macho & 56 & 45 & 80,36 \\
\hline Total & 9933 & 80 & 80,81 \\
\hline
\end{tabular}

\subsection{Considerações sobre os resultados obtidos}

Com base nos resultados obtidos pela rede MLP, primeiramente, analisou-se a classificação dos grupos genéticos referente à técnica de CPMG. O primeiro estudo para a separação dos grupos genéticos manteve as fêmeas como padrões fixos enquanto os machos eram alterados (AXTA, BXTA, CXTA e AXTS, BXTS CXTS). Nesta classificação a rede não teve um bom desempenho, acertando menos de $50 \%$ para cada grupo. Isso pode ter acontecido por diversos fatores, tais como os animais terem a mesma idade e suas carnes serem moles, comparadas a carnes de animais mais velhos, pois os dados provenientes dessas amostras são muito parecidos.

Já os resultados obtidos com a utilização dos touros como padrões fixos (AXTA e AXTS; BXTA e BXTS; CXTA e CXTS) foram significativos. Os grupos genéticos AX e CX tiveram 77,14\% e 64,29\% de separação, respectivamente, mas o grupo BX acertou apenas $44,44 \%$.

Analisando os resultados alcançados com a classificação dos grupos genéticos, referente à técnica de CWFP, observamos que os resultados desta técnica foram muito parecidos com os resultados alcançados pela técnica de CPMG. Os resultados obtidos quando mantemos as fêmeas fixas e alteramos os machos, também não foram satisfatórios, ficando abaixo dos 50\%. Mas, nos resultados do 
segundo estudo dos grupos genéticos, onde foram mantidos os machos fixos, apenas o grupo $A X$ teve um menor resultado (66\% de acerto), quando comparados com a técnica de CPMG (77\% de acerto). A porcentagem de acerto dos grupos BX e CX foram de $52,78 \%$ e $75,00 \%$, respectivamente.

Como mencionado anteriormente, fêmeas e machos apresentam diferenças no teor de gordura subcutânea e isso se tornou um diferencial na classificação do sexo. A rede MLP conseguiu predizer o sexo dos bovinos com uma precisão de $83,84 \%$ e $80,81 \%$, baseado nas curvas de decaimentos dos dados de CPMG e CWFP, respectivamente. 


\section{Conclusões gerais e trabalhos futuros}

\subsection{Conclusões gerais}

A rede MLP conseguiu classificar padrões a partir dos dados obtidos por ressonância magnética. Os atributos de entrada utilizados pela rede demonstraram que as seqüências de pulsos fornecidas pela espectroscopia de RMN exprimem de forma qualitativa as características das amostras analisadas.

Mesmo não obtendo o desempenho desejado com a classificação dos grupos genéticos baseados nos dados de TA e TS, os resultados foram considerados significativos com as classificações dos grupos genéticos AX, BX e CX e do sexo dos animais. A rede MLP utilizada na classificação do sexo dos animais foi capaz de acertar pouco mais de 8 em cada 10 amostras analisadas. Isso indica que a mesma é capaz de detectar pequenas diferenças nas amostras de carne. Esses resultados tornam-se significativos visto que estes animais depois de desmamados foram automaticamente levados ao confinamento e abatidos precocemente.

Um dos diferenciais da abordagem proposta foi a utilização de informações colhidas diretamente da espectroscopia de RMN, contribuindo para o uso da mesma em aplicações que exigem análises em tempo real. 


\subsection{Trabalhos futuros}

Com o intuito de melhorar o método de controle de qualidade da carne utilizado atualmente e dos dados apresentados neste trabalho, propõe-se como trabalhos futuros a utilização de outras abordagens de redes neurais ou, até mesmo, fazer uso de algum método de pré-processamento para a rede MLP utilizada nessa dissertação.

Análise de componentes principais (PCA - Principal Component Analysis) pode ser utilizada como um pré-processamento para redes neurais por ser um método que utiliza combinações lineares para a redução de dados.

Algumas outras abordagens de redes neurais que podem ser utilizadas neste trabalho são as redes RBF (do inglês Radial Basis Function) e LVQ (do inglês Learning Vector Quantization), sendo que ambas são também aplicadas em problemas de reconhecimento de padrões. 


\section{Referências Bibliográficas}

[1] http://www.abiec.com.br/imprensa.asp?id news=354: acessado em 13/12/2006.

[2] NORDON, A.; McGILL, C. A.; LITTLEJOHN D. Process NMR spectrometry, Analyst, Vol. 126, No. 2, pp. 260-272, 2001.

[3] GIL, V. M. S.; C. GERALDES, C. F. G. Ressonância Magnética Nuclear. Fundamentos, Métodos e Aplicações, Lisboa, Fundação Calouste, 1987.

[4] AZEREDO, R. B. V. Espectroscopia de RMN no Estado Estacionário. São Carlos. Instituto de Química de São Carlos, USP, Dissertação (Mestrado), 1999.

[5] VenÂnCIO, T.; ENGELSBERG, M.; AZEREDO, R. B. V; COlNAGO, L. A. Thermal diffusivity and nuclear spin relaxation: $A$ continuous wave free precession NMR study. Journal of Magnetic Resonance, Vol. 181, pp. 29-34, 2006. 
[6] GUNASEKAREN, S. Nondestrutive Food Evaluation: Techniques to Analyses Properties and Quality, New York, M. Dekker, 2001.

[7] BERTRAM, H. C. Field gradient CPMG applied on postmortem muscles. Magnetic Resonance Imaging, Vol. 22, pp. 557-563, 2004.

[8] MIQUEL, M. E.; HALL, L. D. A. General survey of chocolate confectionery by magnetic resonance imaging. Lebensm. -Wiss. u.-Techonol, Vol. 31, pp. 9399, 1998.

[9] HAYKIN, S. Neural Networks: A Comprehensive Foundation, Second Edition, McMaster University, Hamilton, Ontario, Canada, 1999

[10] BRAGA, A. P.; LUDERMIR, T. B.; CARVALHO, A. C. P. L. F. Redes Neurais Artificiais, Teorias e Aplicações. 1 Ed. LTC - Livros Técnicos e Científicos Editora S.A., 2000.

[11] WITTEN, I. H.; FRANK, E. Data Mining: Practical Machine Learning Tools and Techniques, Second Edition, Morgan Kaufmann, San Francisco, 2005.

[12] http://www.criareplantar.com.br/noticia/ler/?idNoticia=1012: acessado em 11/12/2006.

[13] COLNAGO, L. A; FORATO, L. A.; TULLIO, R. R.; CRUZ, G. M. Avaliação da qualidade de carne e derivados por ressonância magnética nuclear. III 
Simpósio sobre qualidade de carne, I Simpósio internacional sobre qualidade de carne.

[14] AZEREDO, R. B. V. Espectroscopia de RMN CWFP. São Carlos, Tese (Doutorado) - Instituto de Química de São Carlos, Universidade de São Paulo, 2004.

[15] HICKEY, H.; MACMILLAN, B.; NEWLING, B.; RAMESH, M.; EIJCK, P. V.; BALCOM, B. Magnetic resonance relaxation measurements to determine oil and water content in fried foods. Food Research International, Vol. 39, pp. 612-618, 2006.

[16] ANDRIGHETtO, C.; JORGE, A. M.; ROÇA, R. O.; SARTORI, D. R.; RODRIGUES, E.; BIANCHINI, W. Maturação da carne bovina. Revista Eletrônica de Veterinária REDVET, ISSN 1695-7504, Vol. VII, No. 06, 2006.

[17] CORRÊA, C. C. Avaliação da Qualidade de Carne Bovina por RMN em Baixa Resolução. Universidade de São Paulo e Embrapa Instrumentação Agropecuária, 2005.

[18] FERREIRA, E. J. Abordagem Genética Para Seleção de Um Conjunto Reduzido de Características Para Construção de Ensembles de Redes Neurais: Aplicações à Língua Eletrônica, Instituto de Ciências Matemáticas e de Computação de São Carlos, USP, Dissertação (Mestrado), 2005. 
[19] O'Farrell, M.; Lewis, E.; Flanagan, C.; Lyons, W. B.; Jackman, Comparison of $k-N N$ and neural network methods in the classification of spectral data from an optical fibre-based sensor system used for quality control in the food industry. Sensors and Actuators B: Chemical, Vol. 111, pp. 354-362, 2005.

[20] SHERIDAN, C.; O'FARRELL, M.; LEWIS, E.; LYONS, W. B.; FLANAGAN, C.; E JACKMAN, N. Monitoring food quality using an optical fibre based sensor system - a comparison of Kohonen and back-propagation neural network classification techniques. Measurement Science and Technology, Vol. 17, pp. 229-234, 2006.

[21] KUPONGSAK, S.; TAN, J. Application of fuzzy set and neural network techniques in determining food process control set points. Fuzzy Sets and Systems, Vol. 157, pp. 1169-1178, 2006.

[22] VEnÂNCIO, T.; ENGELSBERG, M.; AZEREDO, R. B. V.; ALEM, N. E. R.; COLNAGO, L. A. Fast and simultaneous measurement of longitudinal and transverse NMR relaxation times in a single continuous wave free precession experiment. Journal of Magnetic Resonance, Vol. 173, pp. 34-36, 2005.

[23] LACHENMEIER, D. W.; FRANK, W.; HUMPFER, E.; SCHAFER, H.; KELLER, S.; MORTTER, M.; SPRAUL, M. Quality control of beer using highresolution nuclear magnetic resonance spectroscopy and multivariate analysis. Eur Food Res Techonol, Vol. 220, pp. 215-221, 2005. 
[24] VEnÂNCIO, T. Novas Aplicações da Precessão Livre em Ondas Contínuas em Ressonância Magnética Nuclear de Baixa e Alta Resolução. São Carlos. Instituto de Química de São Carlos, USP, 152 p. Tese (Doutorado), 2006.

[25] BONAGAMBA, T. J.; CAPELLE, K. W.; AZEVEDO, E. R. A RMN e suas aplicações atuais. Ciência Hoje, Vol. 37, No. 221, pp. 40-48, 2005.

[26] O'FARRELL, M.; LEWIS, E.; LYONS, W. B.; JACKMAN, N. Combining principal component analysis with an artificial neural network to perform online quality assessment of food as it cooks in a large-scale industrial oven. Sensors and Actuators B: Chemical, Vol. 107, pp. 104-112, 2005.

[27] ABULARACH, M. L. S.; ROCHA, C. E.; FELíCIO, P. E. Características de qualidade do contrafilé de touros jovens da raça nelore, Ciência e Tecnologia de Alimentos, Vol. 18, No. 2, pp. 205-210, 1998.

[28] GESTAL, M.; GÓMEZ-CARRACEDO, M. P.; ANDRADE, J. M.; DORADO, J.; FERNÁNDEZ, E.; PRADA, D.; PAZOS, A. Classification of apple beverages using artificial neural networks with previous variable selection. Analytica Chimica Acta, Vol. 524, pp. 225-234, 2004.

[29] http://www.cnpgc.embrapa.br/publicacoes/doc/doc77/ acessado em 18/06/2007. 
[30] COLNAGO, L. A.; TORRE NETO, A.; FERRAZINI, J.; OSTE, R. Espectrômetro de RMN para Análise Quantitativa. INPI, MU7602306-0, 1996.

[31] MONIN, G. Recents methods for predicting quality of whole meat. Meat Science, Vol. 49, pp. 231-243, 1998.

[32] Bertram, H. C.; ANDERSen, R. H.; ANDERSEN, H. J. Development in myofibrillar water distribution of two pork qualities during 10-month freezer storage. Meat Science, Vol. 75, pp. 128-133, 2007.

[33] SORLAND, G. H.; LARSEN, P. M.; LUNDBY, F.; RUDI, A. P.; GUIHENEUF, T. Determination of total and moisture content in meat using low field NMR. Meat Science, Vol. 66, pp. 543-550, 2004.

[34] BERTRAM, H. C.; AASLYNG, M. D.; ANDERSEN, H.J. Elucidation of the relationship between cooking temperature, water distribution and sensory attributes of pork - a combined NMR and sensory study. Meat Science, Vol. 70, pp. 75-81, 2005.

[35] BERTRAM, H. C.; KOHLER, A.; BOCKER, U.; OFSTAD, R.; ANDERSEN, H. J. Heat-induced changes in myofibrillar protein structures and myowater of two pork qualities. A combined FT-IR spectroscopy and low-field NMR relaxometry study. Journal of Agricultural and Food Chemistry, Vol. 54, pp. 170-176, 2006. 
[36] BERTRAM H. C.; WU, Z.; BERG, F. V.; ANDERSEN, H.J. NMR relaxometry and differential scanning calorimetry during meat cooking. Meat Science, Vol. 74, pp. 684-689, 2006.

[37] BRONDUM, J.; MUNCK, L.; HENCKEL, P.; KARLSSON, A.; TORNBERG, E.; ENGELSEN. S. B. Prediction of water-holding capacity and composition of porcine meat by comparative spectroscopy. Meat Science, Vol. 55, pp. 177-185, 2000. 


\section{APÊNDICE A - Funcionamento do WEKA}

Waikato Environment for Knowledge Analysis (WEKA) é uma ferramenta de que contempla uma série de algoritmos de preparação de dados, de aprendizagem de máquina (mineração) e de validação de resultados. WEKA foi desenvolvido na Universidade de Waikato na Nova Zelândia, sendo escrito em Java e possuindo código aberto disponível na Web, http://www.cs.waikato.ac.nz/ml/weka/.

O sistema possui uma interface gráfica amigável e seus algoritmos fornecem relatórios com dados analíticos e estatísticos do domínio minerado. Grande parte de seus recursos é acessível via sua GUI (Graphical User Interface), sendo que os demais podem ser utilizados por intermédio de APl's (Application Programming Interfaces). Foi disponibilizada também uma abrangente documentação online do código fonte. Por ser escrito em Java, o código pode ser executado em diferentes plataformas, conferindo uma boa portabilidade ao software.

A seguir serão apresentados alguns métodos implementados no WEKA. Método de Classificação:

- Árvore de decisão induzida

- Regras de aprendizagem

- Tabelas de decisão

- Regressão local de pesos

- Aprendizado baseado em instância

- Regressão lógica

- Perceptron 
- Perceptron multicamadas

- Comitê de perceptrons

- SVM (Support Vector Machine)

Métodos para Predição Numérica:

- Regressão linear

- Geradores de árvores modelo

- Regressão local de pesos

- Aprendizado baseado em instância

- Tabelas de decisão

- Perceptron multicamadas

O WEKA possui um formato próprio, denominado ARFF (Attribute-Relation File Format), o qual temos que descrever o domínio do atributo, pois o mesmo não pode ser obtido automaticamente pelo seu valor. Antes de aplicar os dados a qualquer algoritmo do pacote WEKA, estes devem ser convertidos para o formato ARFF.

Como exemplo, temos os dados armazenados em uma planilha do Microsoft Excel e para salvar o exemplo no formato texto, utilizou-se o editor Microsoft Word. Pode-se também utilizar outros programas para converter os dados para o formato ARFF. A planilha do Microsoft Excel contendo dados atmosféricos é apresentada na Figura A.1. 


\begin{tabular}{|c|c|c|c|c|c|c|}
\hline \multicolumn{5}{|c|}{ 図]dados_clima.txt } & \multicolumn{2}{|c|}{$-|\square| x \mid$} \\
\hline & A & $\mathrm{B}$ & c & D & $E$ & $\bar{\Delta}$ \\
\hline 1 & Céu & temperatura & umidade & vento & jogar & \\
\hline \multicolumn{7}{|l|}{2} \\
\hline 3 & sol & 85 & 85 & FALSO & nẵo & \\
\hline 4 & sol & 80 & 90 & VERDADEIRO & não & \\
\hline 5 & nublado & 83 & 86 & FALSO & sim & \\
\hline 6 & chuva & 70 & 96 & FALSO & $\operatorname{sim}$ & \\
\hline 7 & chuva & 68 & 80 & FALSO & $\operatorname{sim}$ & \\
\hline 8 & chuva & 65 & 70 & VERDADEIRO & กล̃̃o & \\
\hline 9 & nublado & 64 & 65 & VERDADEIRO & $\operatorname{sim}$ & \\
\hline 10 & sol & 72 & 95 & FALSO & nã̃o & \\
\hline 11 & sol & 69 & 70 & FALSO & sim & \\
\hline 12 & chuva & 75 & 80 & FALSO & sim & \\
\hline 13 & sol & 75 & 70 & VERDADEIRO & sim & \\
\hline 14 & nublado & 72 & 90 & VERDADEIRO & sim & \\
\hline 15 & nublado & 81 & 75 & FALSO & sim & \\
\hline 16 & chuva & 71 & 91 & VERDADEIRO & nã̃o & \\
\hline \multicolumn{7}{|l|}{17} \\
\hline 18 & & & & 1 & & \\
\hline 15 & & & & & & \\
\hline
\end{tabular}

FIGURA A.1 - Dados armazenados em formato de planilha.

Carrega-se 0 arquivo com o Microsoft Word, onde a primeira linha representa o cabeçalho das colunas, ou seja, o nome dos atributos sendo separados por vírgula. As linhas seguintes representam os registros, onde cada atributo do registro também será separado por vírgula, conforme mostra a Figura A.2.

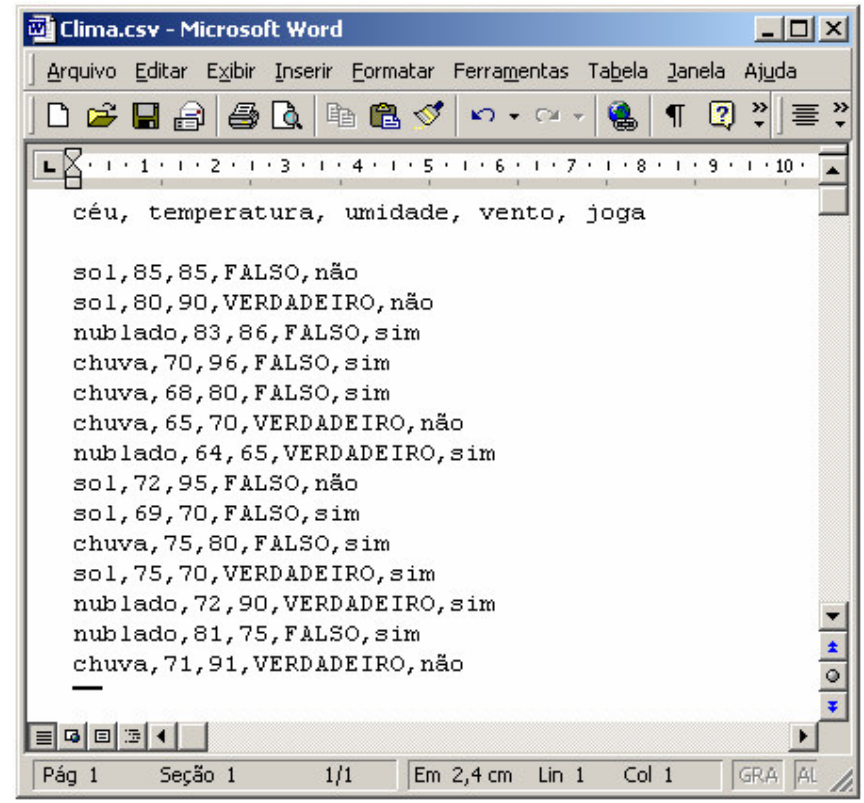

FIGURA A.2 - Dados armazenados em formato de texto. 
Tem-se então na primeira linha o nome do conjunto de dados atribuído pelo comando @relation nome_do_conjuto_de_dados; em seguida, tem-se a relação dos atributos, onde colocamos o nome do atributo e tipo ou seus possíveis valores, definido por @attribute nome_do_atributo tipo ou \{valores\}. Na seção dos dados, coloca-se o comando @data e nas próximas linhas são inseridos os registros, onde cada linha representa um registro. A Figura A.3 ilustra tais formatos.

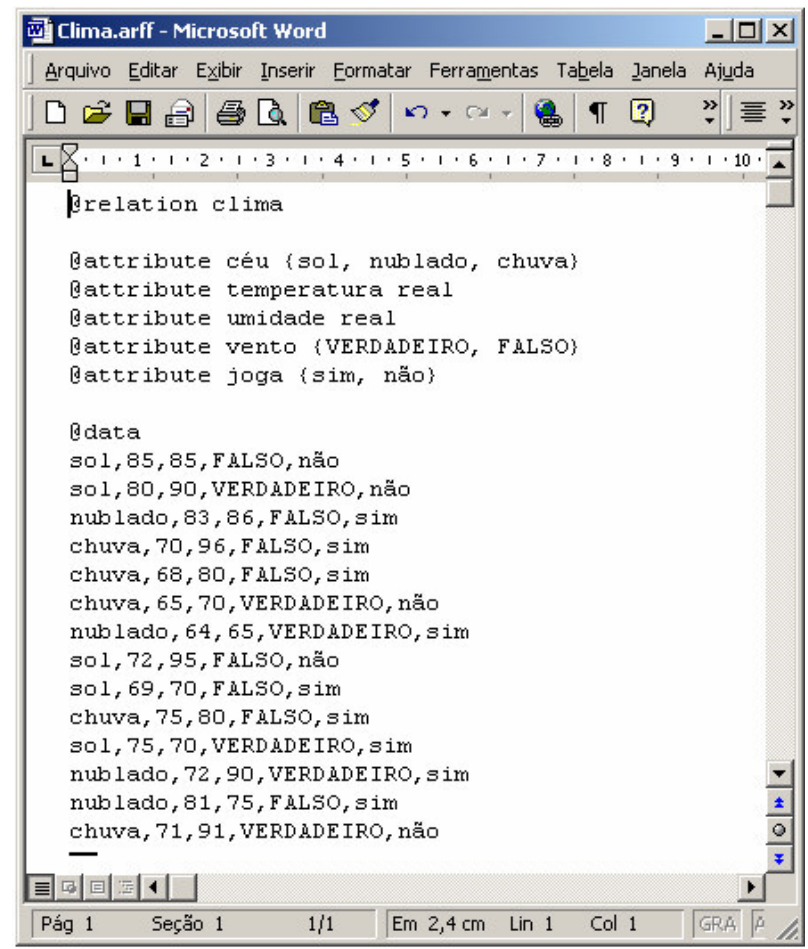

FIGURA A.3 - Dados armazenados em formato ARFF.

O passo seguinte é gravar o arquivo. Para tanto, seleciona-se no menu "Arquivo" a opção "Salvar como...", escolhendo como formato de gravação a opção "Somente texto com quebra de linha" e digitando no campo "Nome do arquivo" o respectivo nome do arquivo com a extensão ".arff". 
A interface gráfica do WEKA disponibiliza grande parte de suas finalidades. Embora seja intuitiva, para uma abordagem inicial, faz-se necessário reconhecer alguns elementos estratégicos da GUI Explorer.

A tela apresentada na Figura A.4 ilustra alguns dos elementos de préprocessamento disponibilizados,

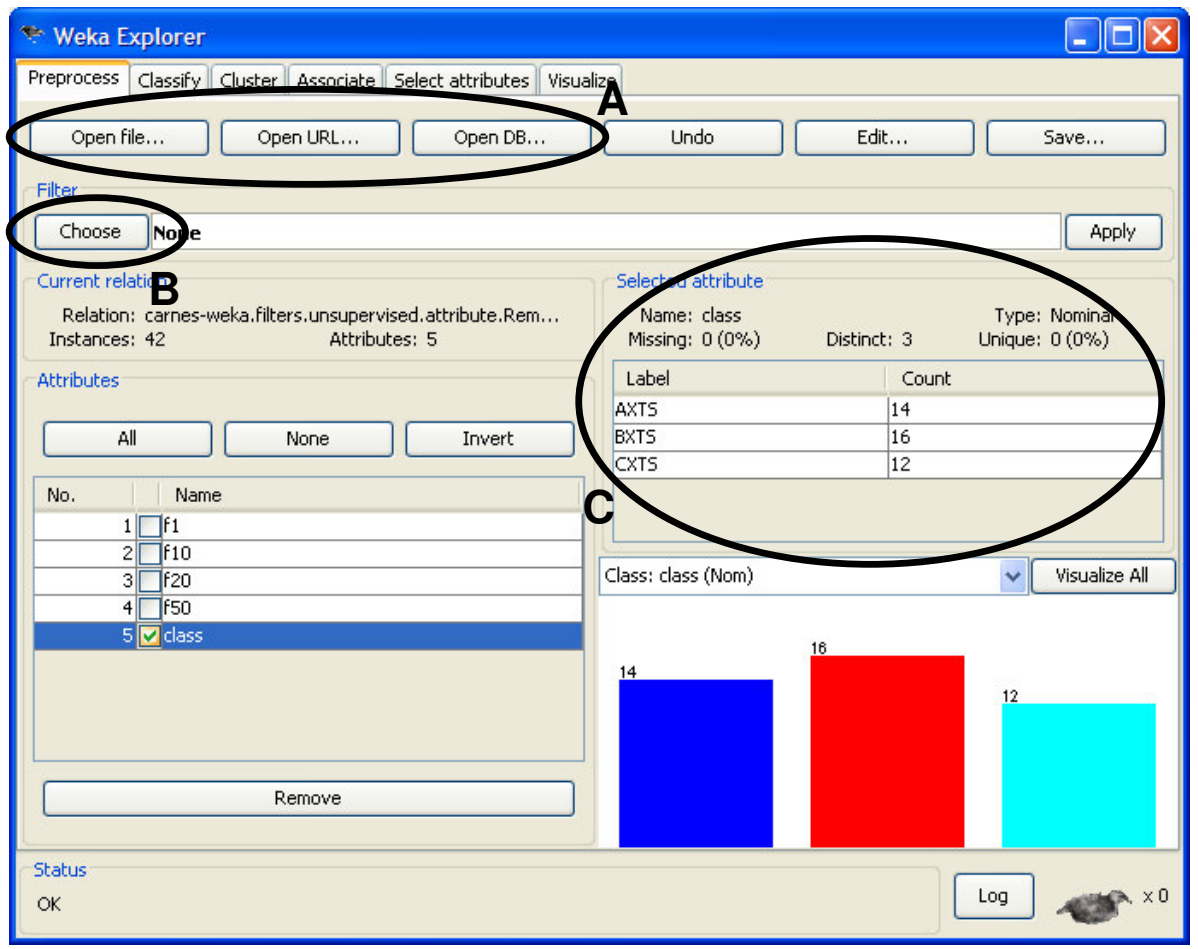

FIGURA A.4 - Ilustração de tarefas de pré-processamento disponibilizadas pelo WEKA.

onde:

- (A) Open File, Open URL, Open DB: através destes botões é possível selecionar, respectivamente, base de dados a partir de flat files locais (formato .arff), bases remotas (Web), e diferentes bancos de dados via Java Database Connectivity (JDBC); 
- (B) No botão filter é possível efetuar sucessivas filtragens de atributos e instâncias na base de dados previamente carregados (seleção, discretização, normalização, amostragem, dentre outros);

- (C) Navegando interativamente pelos atributos (quadro attributes) é possível obter informações quantitativas e estatísticas sobre os mesmos (quadro Selected attribute).

Na tela gráfica apresentada na Figura A.5 é possível executar as tarefas de classificação,

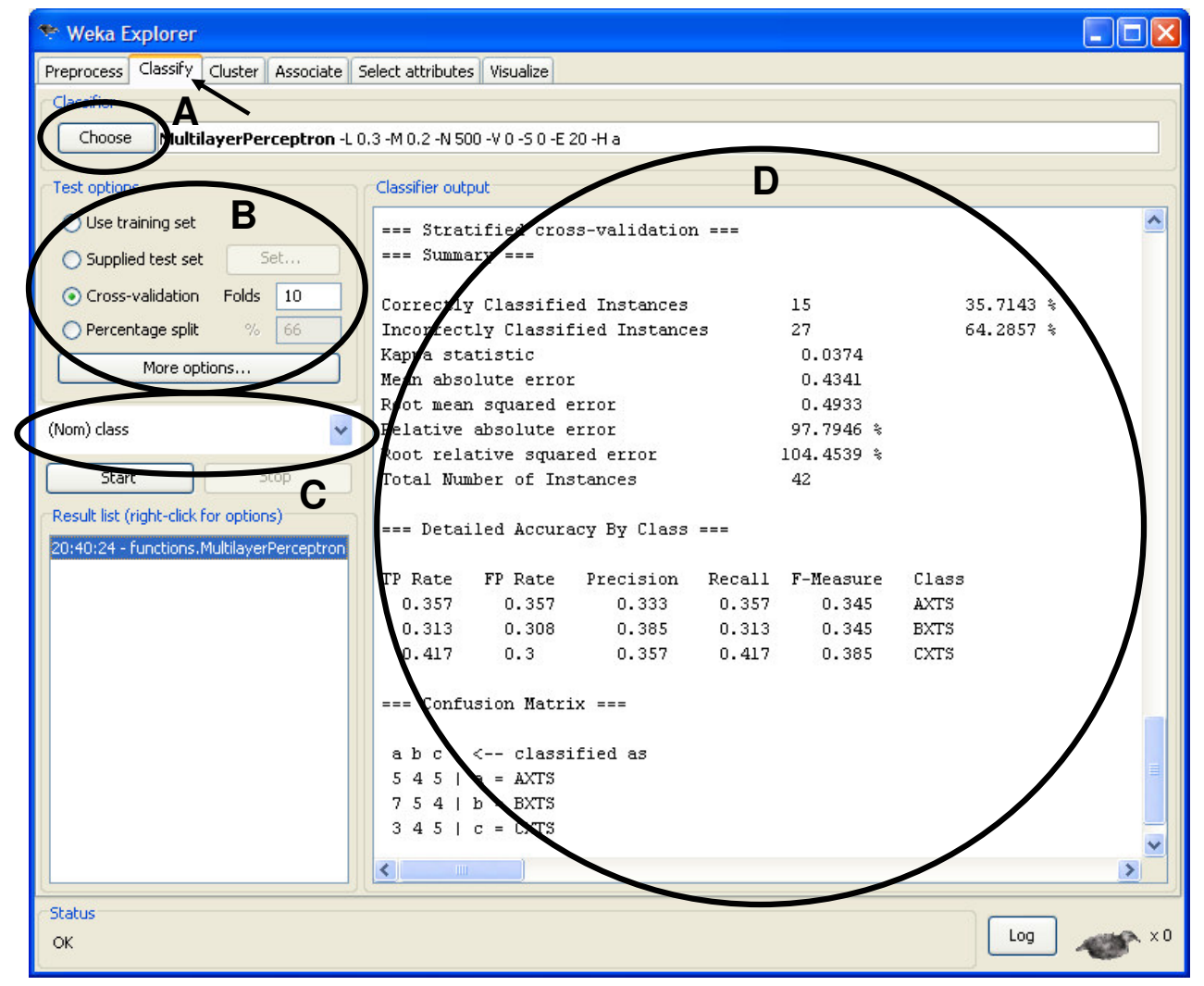

FIGURA A.5 - Ilustração de tarefas de classificação disponibilizadas pelo WEKA. 
onde:

- (A) Seleção e parametrização do algoritmo a ser utilizado (Id3, C45, J48, BayesNet, Prism, Part etc);

- (B) Permite selecionar a opção de teste e validação do modelo gerado (o próprio conjunto de dados do treinamento, um outro conjunto só para testes, cross-validation, separar parte do conjunto de treinamento para teste);

- (C) Seleção do atributo classe para a tarefa de classificação;

- (D) Resumo da tarefa efetuada, com dados estatísticos, modelo, matriz de confusão etc.

As opções "Cluster", "Associate" e "Select attributes" no menu principal possuem interfaces semelhantes, fornecendo algumas opções peculiares a tais tarefas. No caso de tarefas de agrupamento ("Cluster") a interface fornece a opção de ignorar atributos, pois é muito comum que neste tipo de tarefa um ou mais atributos gerem viés ou ruídos no processo de agrupamento. Já na seleção de atributos ("Select attributes"), ilustrada na Figura A.6, torna-se possível escolher o algoritmo avaliador de atributos e o método de busca para a tarefa. Faz-se necessário salientar que alguns avaliadores demandam métodos de busca específicos. 


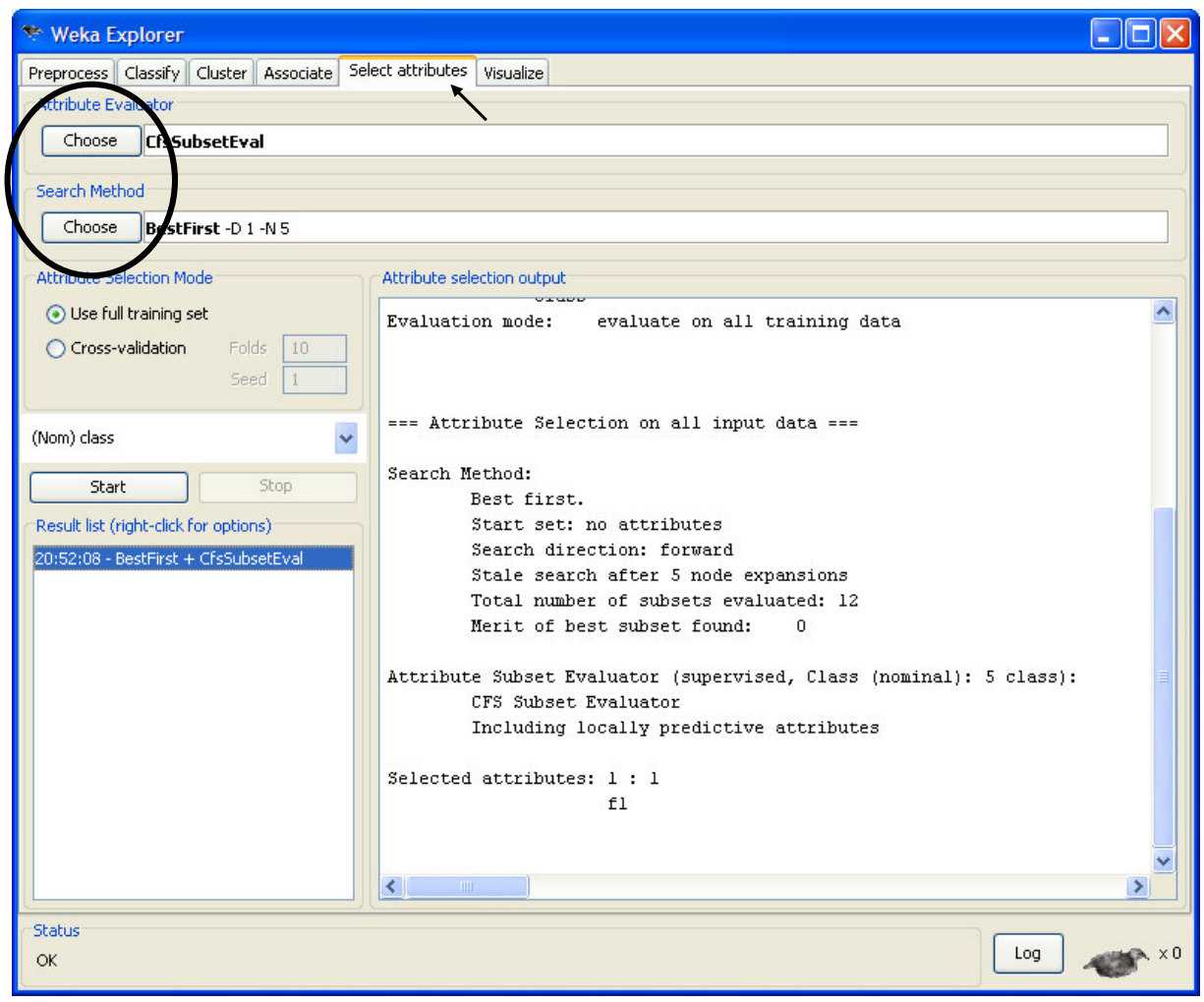

FIGURA A.6 - Ilustração da janela de seleção de atributos do WEKA. 